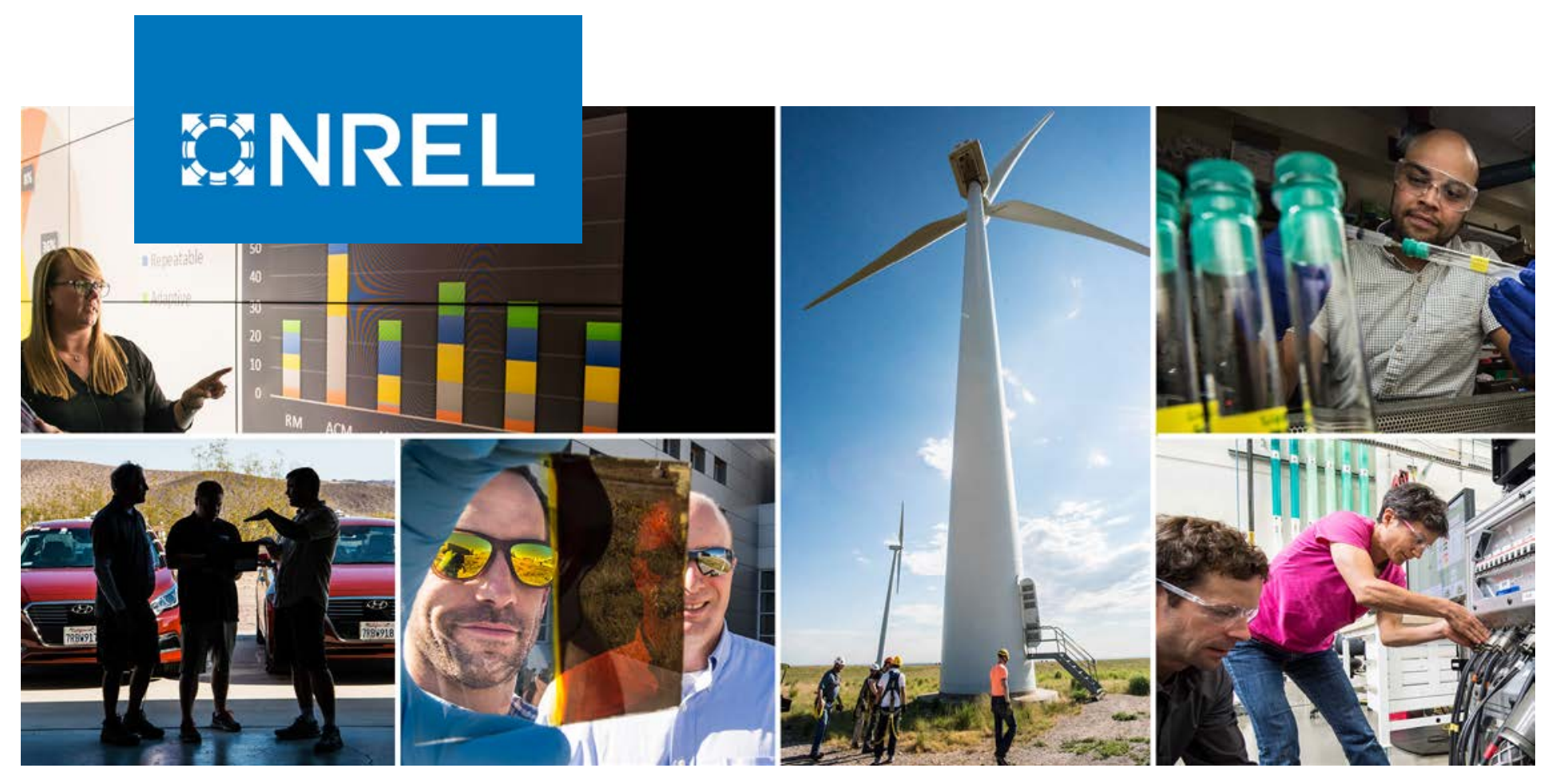

\title{
Submarine Cable Analysis for U.S. Marine Renewable Energy Development
}

Ben Best ${ }^{1}$ and Levi Kilcher ${ }^{2}$

${ }^{1}$ Ecoquants, LLC

${ }^{2}$ National Renewable Energy Laboratory

NREL is a national laboratory of the U.S. Department of Energy

Office of Energy Efficiency \& Renewable Energy

Operated by the Alliance for Sustainable Energy, LLC

This report is available at no cost from the National Renewable Energy Laboratory (NREL) at www.nrel.gov/publications.
Technical Report

NREL/TP-5000-71125

November 2019 


\section{FNREL}

\section{Submarine Cable Analysis for U.S. Marine Renewable Energy Development}

Ben Best ${ }^{1}$ and Levi Kilcher ${ }^{2}$

${ }^{1}$ Ecoquants, LLC

${ }^{2}$ National Renewable Energy Laboratory

\section{Suggested Citation}

Best, Ben, and Levi Kilcher. 2019. Submarine Cable Analysis for U.S. Marine Renewable Energy Development. Golden, CO: National Renewable Energy Laboratory.

NREL/TP-5000-71125. https://www.nrel.gov/docs/fy20osti/71125.pdf.

NREL is a national laboratory of the U.S. Department of Energy Office of Energy Efficiency \& Renewable Energy Operated by the Alliance for Sustainable Energy, LLC

This report is available at no cost from the National Renewable Energy Laboratory (NREL) at www.nrel.gov/publications.

Contract No. DE-AC36-08GO28308
Technical Report NREL/TP-5000-71125

November 2019

National Renewable Energy Laboratory 15013 Denver West Parkway Golden, CO 80401 303-275-3000 • www.nrel.gov 


\section{NOTICE}

This work was authored by the National Renewable Energy Laboratory, operated by Alliance for Sustainable Energy, LLC, for the U.S. Department of Energy (DOE) under Contract No. DE-AC36-08GO28308. Funding provided by the U.S. Department of Energy Office of Energy Efficiency and Renewable Energy Water Power Technologies Office. The views expressed herein do not necessarily represent the views of the DOE or the U.S. Government.

This report is available at no cost from the National Renewable Energy Laboratory (NREL) at www.nrel.gov/publications.

U.S. Department of Energy (DOE) reports produced after 1991 and a growing number of pre-1991 documents are available free via www.OSTI.gov.

Cover Photos by Dennis Schroeder: (clockwise, left to right) NREL 51934, NREL 45897, NREL 42160, NREL 45891, NREL 48097, NREL 46526.

NREL prints on paper that contains recycled content. 


\section{Acknowledgments}

The authors would like to extend thanks to National Renewable Energy Laboratory technical staff who contributed to this study, especially Walter Musial and Suzanne Tegen. Significant improvements to the report were provided by the U.S. Department of Energy from Gary Norton and Simon Gore. Neil Rondorf, former chair of the International Cable Protection Committee, was especially helpful in providing background and context for the submarine cable industry. Jason Busch of Pacific Ocean Energy Trust shared valuable perspectives from the marine renewable energy industry. 


\section{Nomenclature or List of Acronyms}

BOEM Bureau of Ocean Energy Management

CFR Code of Federal Regulations

EEZ exclusive economic zone

ICPC International Cable Protection Committee

$\mathrm{kW} / \mathrm{m} \quad$ kilowatt per meter

$\mathrm{m} \quad$ meter

$\mathrm{m} / \mathrm{s} \quad$ meters per second

MHK marine and hydrokinetic (i.e., wave and tidal)

NASCA North American Submarine Cable Association

NOAA National Oceanic and Atmospheric Administration

NREL National Renewable Energy Laboratory

TW terawatt

$\mathrm{TWh} / \mathrm{yr} \quad$ terawatt-hours per year

$\mathrm{W} / \mathrm{m}^{2} \quad$ watt per square meter 


\section{Executive Summary}

This report by the National Renewable Energy Laboratory (NREL) was funded by the U.S. Department of Energy to evaluate potential overlap between U.S. marine renewable energy resources and existing footprints and spatial needs of the U.S. submarine telecommunications cable industry. Submarine cables are vital to the telecommunications industry, and marine renewable energy - including offshore wind, tidal, and wave energy - has the potential to diversify the U.S. renewable energy portfolio, create jobs, and power the emerging blue economy. Marine renewable energy can complement other renewables by offering consistent, reliable energy in high demand times (e.g., during morning and evening hours), and by siting in proximity to coastal areas with high population density. The first U.S. commercial marine renewable energy facility - the Block Island Wind Farm (Rhode Island) - went into production in December 2016. As implementation and other costs for these technologies continue to drop and increasingly ambitious targets for renewable energy are adopted, marine renewable energy planning and development will need to effectively evaluate the presence of co-occurring ocean uses and resources, like submarine cables.

Repair and maintenance of submarine cables require safe access to cables unfettered by structural obstacles, including infrastructure associated with marine renewable energy development. The submarine cable industry handles $95 \%$ of intercontinental internet, data, and voice traffic (Communications Security, Reliability and Interoperability Council IV 2014), thus is vital to the U.S. and global economy. Traditional methods of cable repair require a significant amount of space on the ocean surface, which has motivated the cable industry to recommend "setback" distances (horizontal buffers to either side of cable paths) that define the potential spatial extent of cable repair operations. These cable setbacks hold no legal or regulatory authority, but instead are generally used as best practices or guidelines defining the area over which the cable operator (and more generally the cable industry) has an active stake and potential operational interests.

This work uses publicly available data sets to identify nearly 100,000 kilometers $(\mathrm{km})$ of submarine cable currently installed within the U.S. exclusive economic zone (EEZ). The Code of Federal Regulations (CFR 585.301) specifies that the legal right of way for submarine cables is 100 feet (ft) ( $\sim 30$ meters [m]) to either side of the cable (i.e., $200 \mathrm{ft}$ wide). This narrow corridor has a very small total footprint; currently occupying approximately $0.05 \%$ of the total U.S. EEZ area (Table ES-1). Because this area occupies such a small footprint, the authors chose to present the remainder of this analysis using the cable industry's advised horizontal setback: the maximum of $500 \mathrm{~m}$, or three times the bottom depth (3z setback in Table ES-1). The cable industry advises this setback distance to facilitate cable maintenance and repair.

After applying this $3 z$ horizontal setback, we find it covers approximately 1.3 million square kilometers $\left(\mathrm{km}^{2}\right)$, or $11 \%$ of the $12-$ million $\mathrm{km}^{2}$ U.S. EEZ. The degree of overlap varies by region, as shown in Table ES-1. In the West Coast region, the setback area is relatively high (29.4\%) primarily because of the deep bottom (i.e., a narrow continental shelf). In the Gulf of Mexico region, the setback area is low $(0.6 \%)$, as a result of very few cables and shallow bottom depth. This percent overlap, however, considers the entire EEZ over vast offshore areas too deep and distant from shore to expect marine renewable energy development. 
Table ES-1. U.S. EEZ Area and Cable Setbacks Area by Region

\begin{tabular}{|c|c|c|c|c|c|}
\hline Region & $\begin{array}{c}\text { EEZ Area } \\
\qquad \begin{array}{c}(1,000 \\
\left.\mathrm{km}^{2}\right)\end{array}\end{array}$ & $\begin{array}{r}100-\mathrm{ft} \text { Cak } \\
\left(1,000 \mathrm{~km}^{2}\right)\end{array}$ & $\begin{array}{l}\text { Setback } \\
\text { (\% of EEZ) }\end{array}$ & $\begin{array}{r}3 z \text { Cable } \\
\left(1,000 \mathrm{~km}^{2}\right)\end{array}$ & $\begin{array}{l}\text { Setback } \\
\text { (\% of EEZ) }\end{array}$ \\
\hline Alaska & 3,683 & 1.0 & 0.03 & 238 & 6.5 \\
\hline $\begin{array}{l}\text { Atlantic } \\
\text { Islands }\end{array}$ & 211 & 0.3 & 0.12 & 43 & 20.4 \\
\hline East Coast & 932 & 1.7 & 0.19 & 165 & 17.7 \\
\hline Gulf of Mexico & 1,553 & 0.1 & 0.01 & 9 & 0.6 \\
\hline Hawaii & 2,475 & 1.3 & 0.05 & 419 & 16.9 \\
\hline Pacific Islands & 2,175 & 0.3 & 0.01 & 152 & 7.0 \\
\hline West Coast & 825 & 1.2 & 0.15 & 242 & 29.3 \\
\hline ALL & 11,854 & 5.9 & 0.05 & 1,268 & 10.7 \\
\hline
\end{tabular}

In this report, we compare the $3 z$ setback areas with viable marine renewable energy areas and resources. The marine renewable energy resource data for this analysis are taken from NREL's Wind Prospector ${ }^{1}$ and MHK (marine and hydrokinetic [i.e., wave and tidal]) Atlas. ${ }^{2}$ We applied filters to identify viable resource area following practices established in earlier resource assessments, as shown in Table ES-2 (Haas et al. 2011; Jacobson et al. 2011; Musial et al. 2016). The viable resource area of offshore wind and wave energy occupies a fraction of the total U.S. EEZ (3.9\% and 3.2\%, respectively). This low percentage is because the vast majority of the U.S. EEZ is in waters deeper than $1,000 \mathrm{~m}$ or at a lower resource intensity than considered in this report. In comparison with the "2016 Offshore Wind Energy Resource Assessment for the United States" (Musial et al. 2016), it is worth noting that the Hawaii EEZ in this report is inclusive of the Northward islands extending beyond the strict state waters of Hawaii. The viable tidal resource area is even smaller $(0.014 \%$ of the EEZ), because viable tidal energy sites are found where a geographic constriction between two larger bodies of water accelerates the flow. Even though the viable area of tidal energy is small in comparison to that of offshore wind and wave, the total tidal resource is still sizable due to high resource intensity in that particular area.

The cable setback analysis presented herein uses a "percent area" approach (i.e., percent of technically viable area, in units of square kilometers, that overlaps with the spatial presence and recommended setback distances for cables), rather than a "percent resource" approach (i.e., where units would be terawatt-hours [TWh] per year that overlaps with cables). We take the former approach because there is not currently an efficient methodology for estimating wave and tidal technical resource totals (in units of TWh per year). Therefore, the area-based approach is meant to serve as a consistent proxy for percent reductions in total resource. Furthermore, the analysis presented here only considers grid-scale marine renewable energy development of

\footnotetext{
${ }^{1}$ NREL Wind Prospector: https://maps.nrel.gov/wind-prospector/

${ }^{2}$ NREL MHK Atlas: https://maps.nrel.gov/mhk-atlas
} 
existing technologies, and does not consider technology evolution or refinement of resource intensity, both of which may change the results presented in Table ES-2.

Table ES-2. Definitions of "Viable" Resource Areas for Offshore Wind, Tidal, and Wave Energy, Resource Totals, and Their Cable Setback Overlap in the U.S. EEZ

\begin{tabular}{|c|c|c|c|c|c|c|c|}
\hline & \multirow[t]{2}{*}{$\begin{array}{l}\text { Depth } \\
\text { Filter }\end{array}$} & \multirow[t]{2}{*}{$\begin{array}{l}\text { Resource } \\
\text { Filter }^{3}\end{array}$} & \multirow{2}{*}{$\begin{array}{c}\text { Total } \\
\text { Resource } \\
\text { (TWh/yr) }\end{array}$} & \multicolumn{2}{|c|}{ Viable Area } & \multicolumn{2}{|c|}{$\begin{array}{c}\text { Cable Setback } \\
\text { Overlap }\end{array}$} \\
\hline & & & & $\begin{array}{l}(1,000 \\
\left.\mathbf{k m}^{2}\right)\end{array}$ & (\% EEZ) & $\begin{array}{c}(1,000 \\
\left.\mathrm{km}^{2}\right)\end{array}$ & $\begin{array}{c}(\% \\
\text { Viable } \\
\text { Area) } \\
\end{array}$ \\
\hline $\begin{array}{l}\text { Offshore } \\
\text { Wind }\end{array}$ & $<1,000 \mathrm{~m}$ & $\begin{array}{l}>7 \text { meters } \\
\text { per second }\end{array}$ & 7,200 & 463.0 & $3.9 \%$ & 18 & $4.0 \%$ \\
\hline Tidal & $<100 \mathrm{~m}$ & $\begin{array}{c}>0.5 \\
\text { kilowatts } / \mathrm{m}^{2}\end{array}$ & 450 & 1.7 & $0.014 \%$ & 0.06 & $3.8 \%$ \\
\hline Wave & $<200 \mathrm{~m}$ & $\begin{array}{c}>10 \\
\text { kilowatts } / \mathrm{m}^{2}\end{array}$ & 2,640 & 379.0 & $3.2 \%$ & 3.4 & $0.9 \%$ \\
\hline
\end{tabular}

Nationally, the overlap of viable resource area with cable setbacks is small for all resource types $(\leq 4 \%$, Table ES-2). This overlap tends to be concentrated in particular regions and sites in distinct ways for each resource type. Offshore wind, for example, has a relatively high overlap around the Hawaiian Islands (14\%). This is because of the relatively deep cables between the islands, translating into wide setbacks that overlap with the strong winds there.

Tidal energy, which has a relatively small viable area $\left(1,700 \mathrm{~km}^{2}\right)$ that is two orders of magnitude less than wind or wave (Table ES-2), happens to overlap on the West Coast (21\%); however, the majority of this area $\left(46\right.$ of $\left.69 \mathrm{~km}^{2}\right)$ occurs at the lowest resource intensity (5001,000 watts $/ \mathrm{m}^{2}$ ). This overlapping area is concentrated primarily in Puget Sound where cables pass along the bottom of narrow channels that are viable tidal energy sites. However, it is important to note that measurements have shown that tidal models underestimate resource intensity at some of the most promising tidal energy sites. Therefore, take caution when interpreting these maps of tidal energy resources. As tidal resource models are refined, and technologies evolve to harness energy at lower speeds, the picture of "viable" resource areas may grow.

The overlap of cables with viable wave energy sites is most notable in the West Coast region of the United States, where wide setbacks (deep water offshore of the narrow shelf) overlap with the sizable resource there. Still, the overlap is only $3.1 \%$ of the total viable area in that region, suggesting that cable routes are not likely to be the primary competing-use concern in the region. Furthermore, it is theoretically possible to capture wave energy before or after it propagates through a cable setback area-thereby suggesting that the wave energy resource can still be captured just outside areas of overlap with cables, so the fractional area of overlap overrepresents the reduction in available resource. This concept underscores the challenge of calculating "resource overlap" for wave energy. It is worth noting that in Hawaii, where cable overlap with offshore wind is relatively high, the overlap between wave energy and cable setbacks is small

\footnotetext{
${ }^{3}$ The resource filters are based on long-term (multiyear) averages.

4 The offshore wind total resource is the "technical" resource, which includes filtering by depth and resource intensity. The tidal and wave resource totals are the "theoretically recoverable" resource, and do not include the filters because a methodology for doing so does not currently exist.
} 
$(1 \%)$ because the majority of cable routes are south of the islands, whereas the majority of the viable wave energy resource is to their north.

In summary, overlap between cable setbacks and viable U.S. marine renewable energy resource sites is small $(\leq 4 \%)$, and tends to be concentrated in a few locations where a combination of a large number of cables, cable depth (that translates into setback width), and resource availability create higher than average overlap. Even at these locations, however, it is important to understand that these cable setbacks have no regulatory or legal function, and therefore the presence of cables does not exclude a marine renewable energy site from development. As stated earlier, the legal right-of-way of a cable is only $200 \mathrm{ft}$ wide. Many existing cables, after all, are closer together than setbacks advise, and occasionally cross one another. Furthermore, subsea cables that deliver marine renewable energy power to shore will need to connect to the marine renewable energy facility, thereby becoming an automatic exception to these setback guidelines.

The cable setback maps described herein are intended to alert potential marine renewable energy project developers of locations where cable operators are active stakeholders. When a proposed marine renewable energy site does overlap with an existing cable to some degree, marine renewable energy project developers should consider contacting cable operators early in the project development process to identify options for mitigating risks to cables and the marine renewable energy project. The recommended approach for contacting a cable operator is to reach out to one of the cable industry organizations, such as the North American Submarine Cable Association $^{5}$ or the International Cable Protection Committee. ${ }^{6}$ The recommended cable setback areas discussed in this report have been developed according to traditional methods of submarine cable repair. In the future, new technologies (e.g., cable-repairing remotely operated vehicles) may reduce the width of cable setback recommendations. These avoidance areas are limited to the most recent submarine cable data. Any planners for marine renewable energy should consult the latest electronic navigation charts and contact the cable industry for confirmation.

\footnotetext{
${ }^{5}$ North American Submarine Cable Association: https://www.n-a-s-c-a.org

${ }^{6}$ International Cable Protection Committee: https://www.iscpc.org
} 


\section{Table of Contents}

Acknowledgments .............................................................................................................................ii

Nomenclature or List of Acronyms .................................................................................................. iv

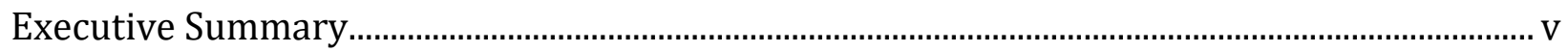

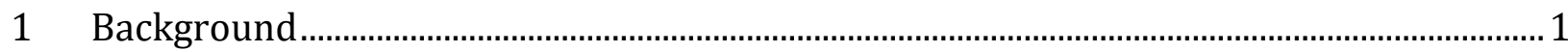

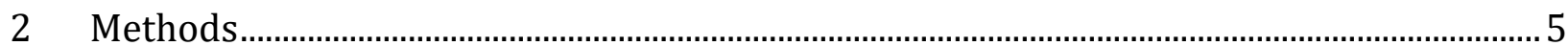

2.1 Study Area, Submarine Cables, Depth, and Energy Data................................................... 5

2.2 Cable-Industry-Advised Submarine Cable Avoidance Zones ............................................ 7

2.3 Depth-Varying Cable Buffer...................................................................................... 8

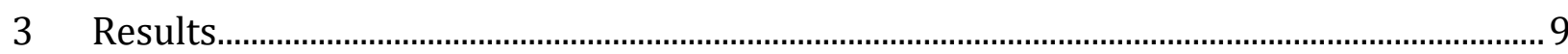

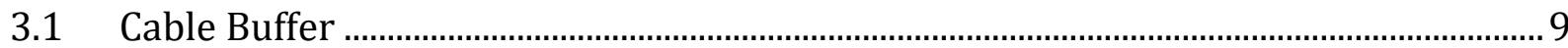

3.2 Overlap of Cable Buffer with Renewable Energy ……………………………………..... 9

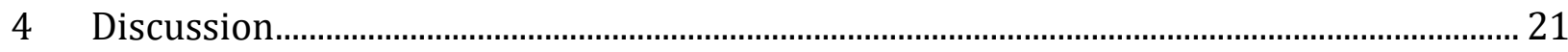

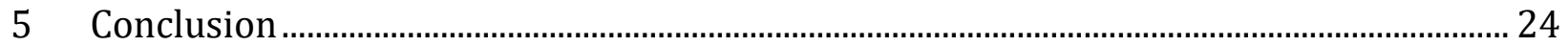

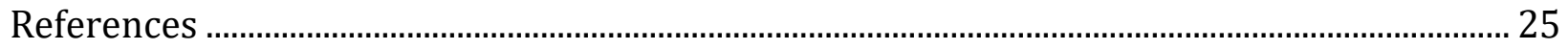

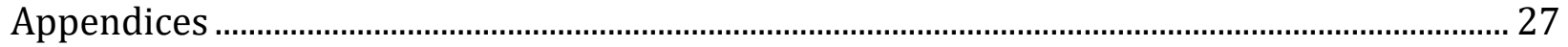

Appendix A. Maps of Tidal Energy and Cable Setback by U.S. Region ..................................... 28

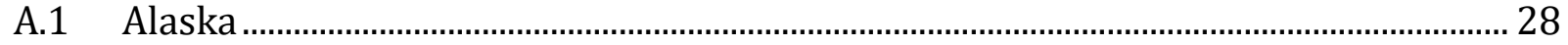

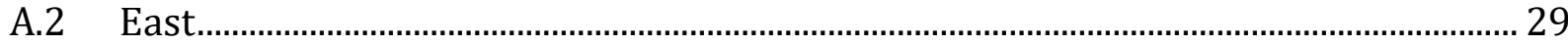

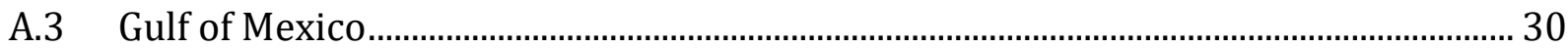

A.4 Puerto Rico......................................................................................................................... 31

A.5 U.S. Virgin Islands ........................................................................................................... 32

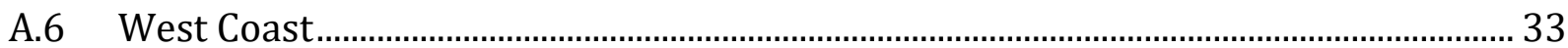

Appendix B. Maps of Wave Energy and Cable Setback by U.S. Region .................................... 34

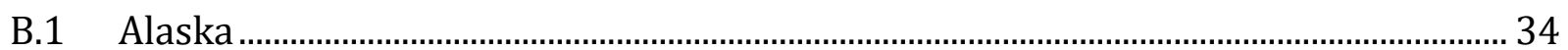

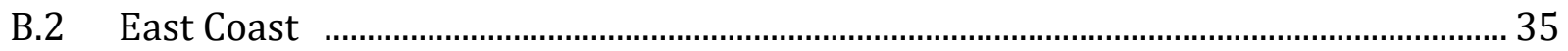

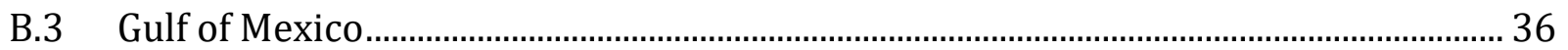

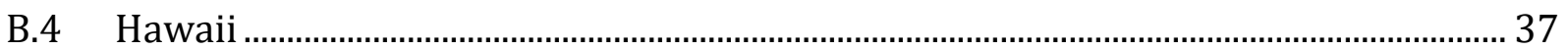

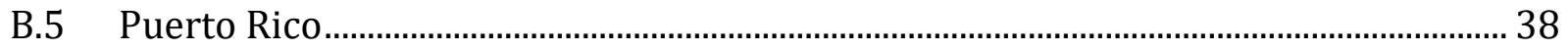

B.6 U.S. Virgin Islands..................................................................................................... 39

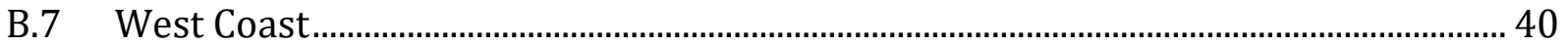

Appendix C. Maps of Wind Energy and Cable Buffer by U.S. Region ...................................... 41

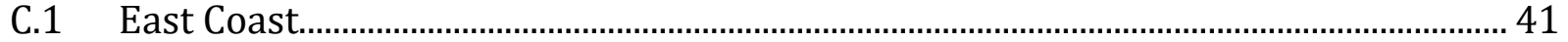

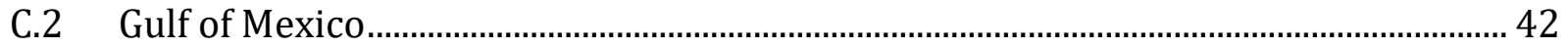

C.3 Hawaii ............................................................................................................................... 43 


\section{List of Figures}

Figure 1. Global operational offshore wind capacity Source: Musial et al. (2019) ..................... 1

Figure 2. Evidence of cost reductions in offshore wind from European strike prices Notes: ${ }^{*}$ Grid and development costs added; ${ }^{* *}$ Grid costs and contract length adjusted Source: Beiter et al. (2017).

Figure 3. Ship operations for submarine cable repair (adapted from Communications Security, Reliability and Interoperability Council IV 2014) .........................................................

Figure 4. Map of National Oceanic and Atmospheric Administration charted submarine

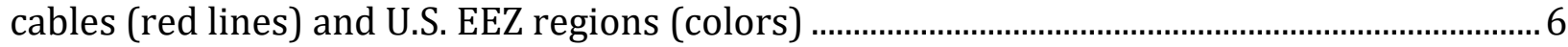

Figure 5. Oblique angle view of cable setback definitions ............................................................... 8

Figure 6. Map of tidal energy resource intensity (green) and advisory $3 z$ cable setbacks (red) in Cook Inlet, Alaska. The background contextual map layer is provided by Esri (2019)

Figure 7. Tidal energy resource intensity (green) and advisory 3z cable setbacks (red) in the Puget Sound area; the purple circle is centered on Admiralty Inlet. The background contextual map layer is provided by Esri (2019).....

Figure 8. Viable wave energy area (green) and advisory 3z cable setbacks (red) in the Cook Inlet, Alaska subregion. The background contextual map layer is provided by Esri (2019) ... 16 Figure 9. Viable wave energy area (green) and advisory $3 \mathrm{z}$ cable setbacks (red) along the Oregon coast. The background contextual map layer is provided by Esri Wind (2019) ........... 17

Figure 10. Viable offshore wind energy area (green) and advisory 3z cable setbacks (red) in Hawaii. The background contextual map layer is provided by Esri (2019) 19

Figure 11. Viable wind energy area (green) and advisory $3 z$ cable setbacks (red) along the mid-Atlantic bight. The background contextual map layer is provided by Esri (2019)............. 20

Figure 12. Screenshot of SubmarineCableMap.com; data include cable owner contact information, cable length, and ready-for-service dates (right)..

Figure 13. U.S. offshore wind project pipeline by project status as of June 2019 Source:

Musial et al. (2019)

Figure 14. Interactive mapping functionality available via the online maps at http://ecoquants.github.io/nrel-cables/maps.html. The background contextual map layer is provided by Esri (2019).

Figure A-1. Map of tidal power in Alaska (green) with submarine cables (black lines) and advisory $3 \mathrm{z}$ setbacks colored by bottom depth (red). The background contextual map layer is provided by Esri (2019)

Figure A-2. Map of tidal power (green) in the East with submarine cables (black lines) and advisory $3 \mathrm{z}$ setbacks colored by bottom depth (red). The background contextual map layer is provided by Esri (2019)

Figure A-3. Map of tidal power (green) in the Gulf of Mexico with submarine cables (black lines) and advisory buffers colored by bottom depth (red). The background contextual map layer is provided by Esri (2019) 
Figure A-4. Map of tidal power (green) in Puerto Rico with submarine cables (black lines) and advisory buffers colored by bottom depth (red). The background contextual map layer is provided by Esri (2019)

Figure A-5. Map of tidal power (green) in the U.S. Virgin Islands with submarine cables (black lines) and advisory buffers colored by bottom depth (red). The background contextual map layer is provided by Esri (2019).

Figure A-6. Map of tidal power (green) in the West Coast with submarine cables (black lines) and advisory buffers colored by bottom depth (red). The background contextual map layer is provided by Esri (2019)

Figure B-1. Map of wave energy (green) in Alaska with submarine cables (black lines) and advisory buffers colored by bottom depth (red). The background contextual map layer is provided by Esri (2019).....

Figure B-2. Map of wave energy (green) on the East Coast with submarine cables (black lines) and advisory buffers colored by bottom depth (red). The background contextual map layer is provided by Esri (2019). 35

Figure B-3. Map of wave energy (green) in the Gulf of Mexico with submarine cables (black lines) and advisory buffers colored by bottom depth (red). The background contextual map layer is provided by Esri (2019).....

Figure B-4. Map of wave energy (green) in Hawaii with submarine cables (black lines) and advisory buffers colored by bottom depth (red). The background contextual map layer is provided by Esri (2019).

Figure B-5. Map of wave energy (green) in Puerto Rico with submarine cables (black lines) and advisory buffers colored by bottom depth (red). The background contextual map layer is provided by Esri (2019)

Figure B-6. Map of wave energy (green) in the U.S. Virgin Islands with submarine cables (black lines) and advisory buffers colored by bottom depth (red). The background contextual map layer is provided by Esri (2019).

Figure B-7. Map of wave energy (green) in the West Coast with submarine cables (black lines) and advisory buffers colored by bottom depth (red). The background contextual map layer is provided by Esri (2019).

Figure C-1. Map of wind speed (green) in the East Coast with submarine cables (black lines) and advisory buffers colored by bottom depth (red). The background contextual map layer is provided by Esri (2019)

Figure C-2. Map of wind speed (green) in the Gulf of Mexico with submarine cables (black lines) and advisory buffers colored by bottom depth (red). The background contextual map layer is provided by Esri (2019)...

Figure C-3. Map of wind speed (green) in Hawaii with submarine cables (black lines) and advisory buffers colored by bottom depth (red). The background contextual map layer is provided by Esri (2019).

Figure C-4. Map of wind speed (green) in the West with submarine cables (black lines) and advisory buffers colored by bottom depth (red). The background contextual map layer is provided by Esri (2019) 


\section{List of Tables}

Table ES-1. U.S. EEZ Area and Cable Setbacks Area by Region .......................................................vi

Table ES-2. Definitions of "Viable" Resource Areas for Offshore Wind, Tidal, and Wave Energy, Resource Totals, and Their Cable Setback Overlap in the U.S. EEZ ................................vii

Table 1. Summary of U.S. Regions Data, including EEZ Area, Cable Lengths, and Availability of Resource Data.................................................................................................................................

Table 2. Area of Regions and Advisory Cable Setback Within the EEZ .......................................... 9

Table 3. Area of Energy and Depth Classes with Advisory 3z Cable Setback Overlap; Across All Assessed Energy Resources ............................................................................................... 10

Table 4. Viable Tidal Resource Area and Advisory Setbacks by Region and Resource Bin .. 12 Table 5. Viable Wave Resource Area and Advisory Setbacks by Region and Resource

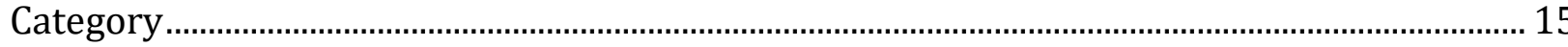

Table 6. Viable Wind Resource Area and Advisory Setbacks by Region and Resource Category 18 


\section{Background}

As demand for diverse resources in the ocean grows, marine planning is increasingly important to minimize conflict. To inform development of wave, tidal, and offshore wind resources (hereafter, referred to collectively as marine renewable energy), the U.S. Department of Energy tasked the National Renewable Energy Laboratory (NREL) with identifying and quantifying ocean use and resource areas overlapping with promising marine renewable energy sites and submarine power and telecommunications cables. The first commercial U.S. marine renewable energy facility - the Block Island Wind Farm (Rhode Island) — went into production in December 2016. Growth in the offshore wind industry is already prominent globally (Figure 1). Marine renewable energy may complement other large-scale renewables by providing energy during high-demand times and in proximity to coastal areas with a high population density. As costs of these technologies continue to drop (Figure 2) and state and local governments set increasingly ambitious targets for renewable energy, marine renewable energy planning and development will need to effectively evaluate the presence of co-occurring ocean uses and resources.

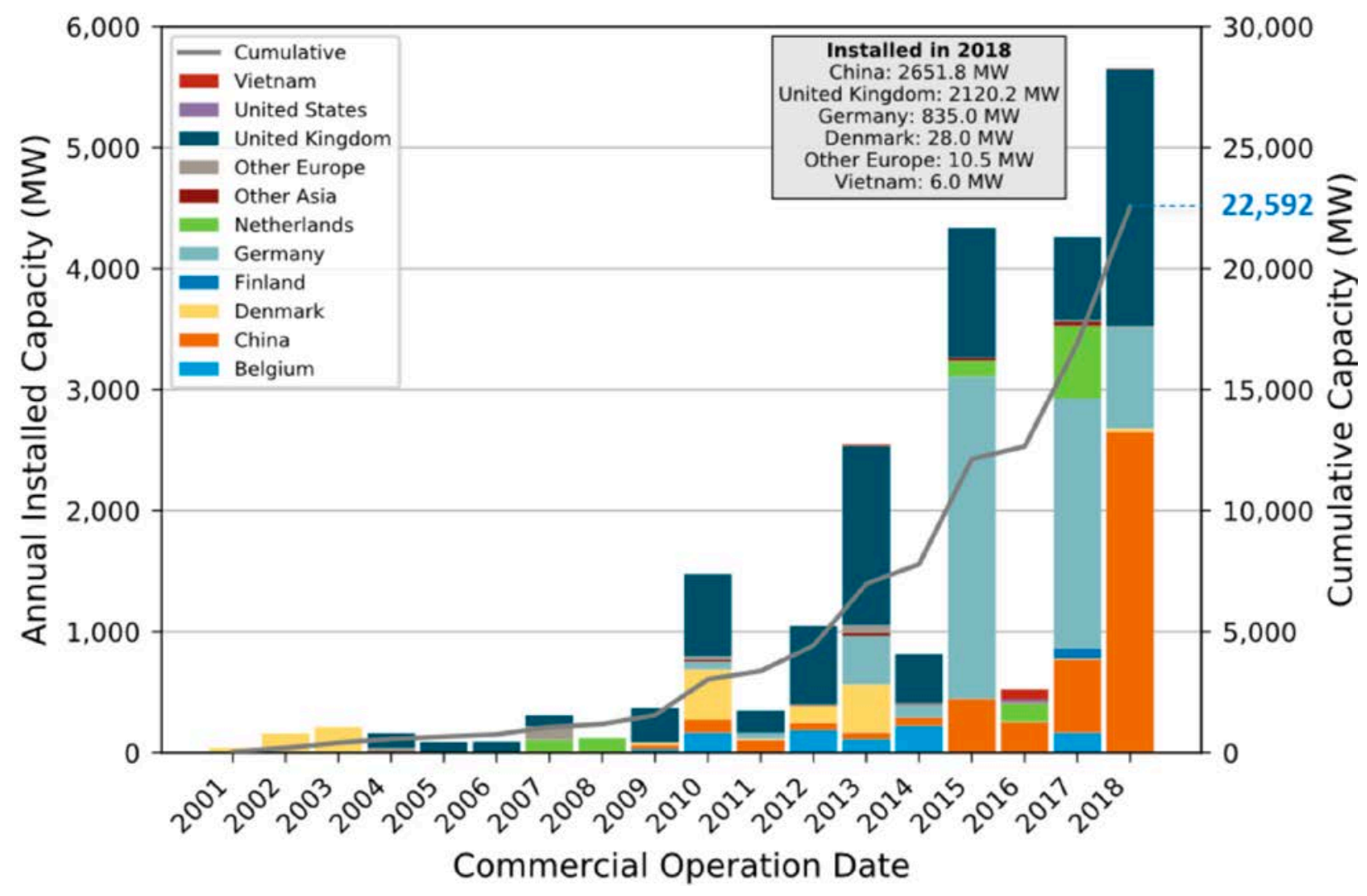

Figure 1. Global operational offshore wind capacity Source: Musial et al. (2019) 


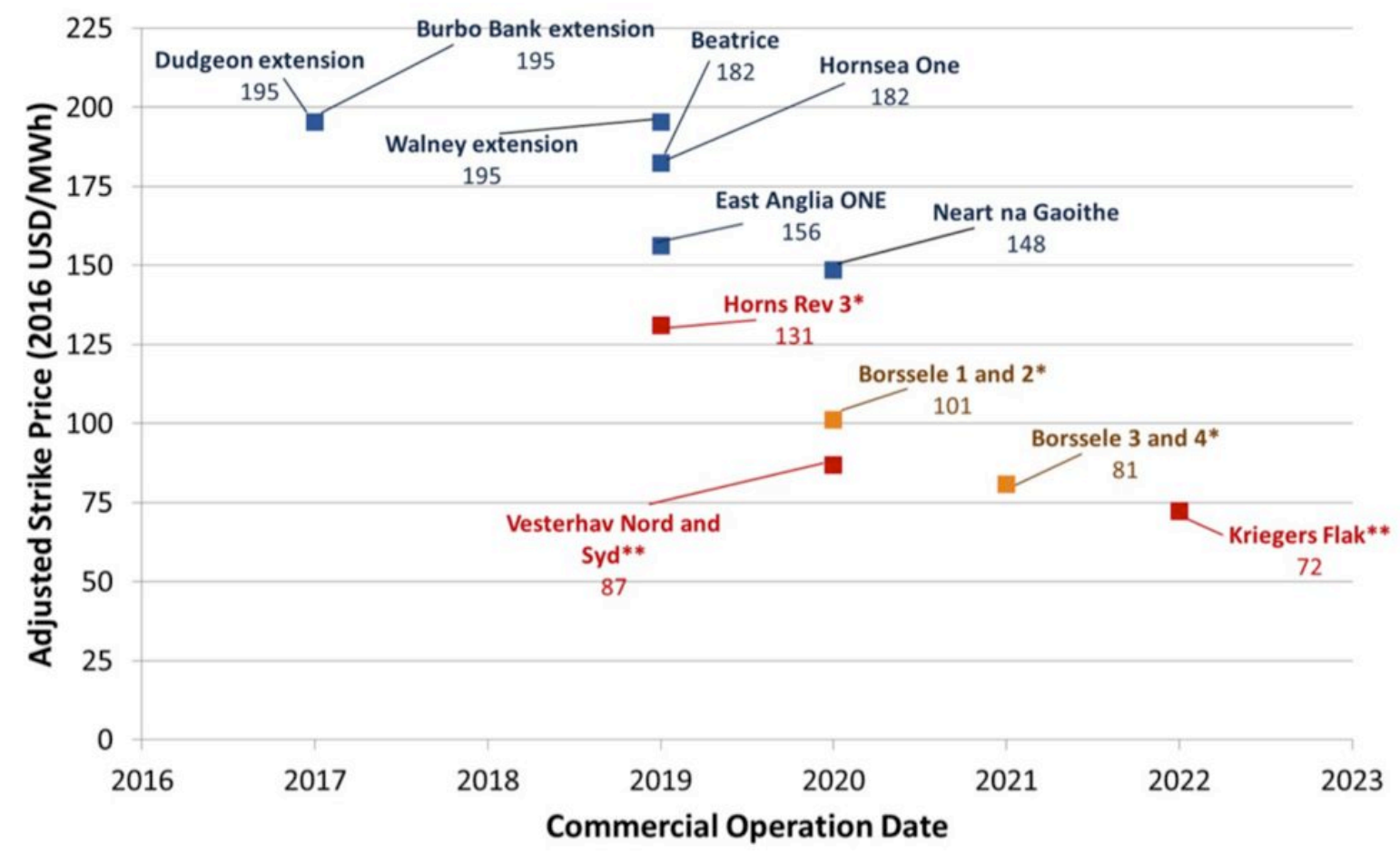

- United Kingdom $\mathbf{m}$ Netherlands $\boldsymbol{\square}$ Denmark

Figure 2. Evidence of cost reductions in offshore wind from European strike prices Notes: *Grid and development costs added; ${ }^{* *}$ Grid costs and contract length adjusted Source: Beiter et al. (2017)

The submarine cable industry handles $95 \%$ of intercontinental internet, data, and voice traffic (Communications Security, Reliability and Interoperability Council IV 2014) and is vital to the U.S. and global economy. Repair of submarine cables traditionally involves grappling the cable with a perpendicular approach and floating it to the surface where the boat can drift (Figure 3). Both of these processes require a horizontal safety setback distance that increases with bottom depth of the submarine cable.

Cable repair (Figure 3) traditionally involves: 1) grappling the ends of the cable (A, C), 2) floating both ends to the surface (B, D), 3) performing repairs (E), and 4) laying down the "splice loop" (not shown). The space required for this work increases with bottom depth (up to a maximum of three times the water depth). 

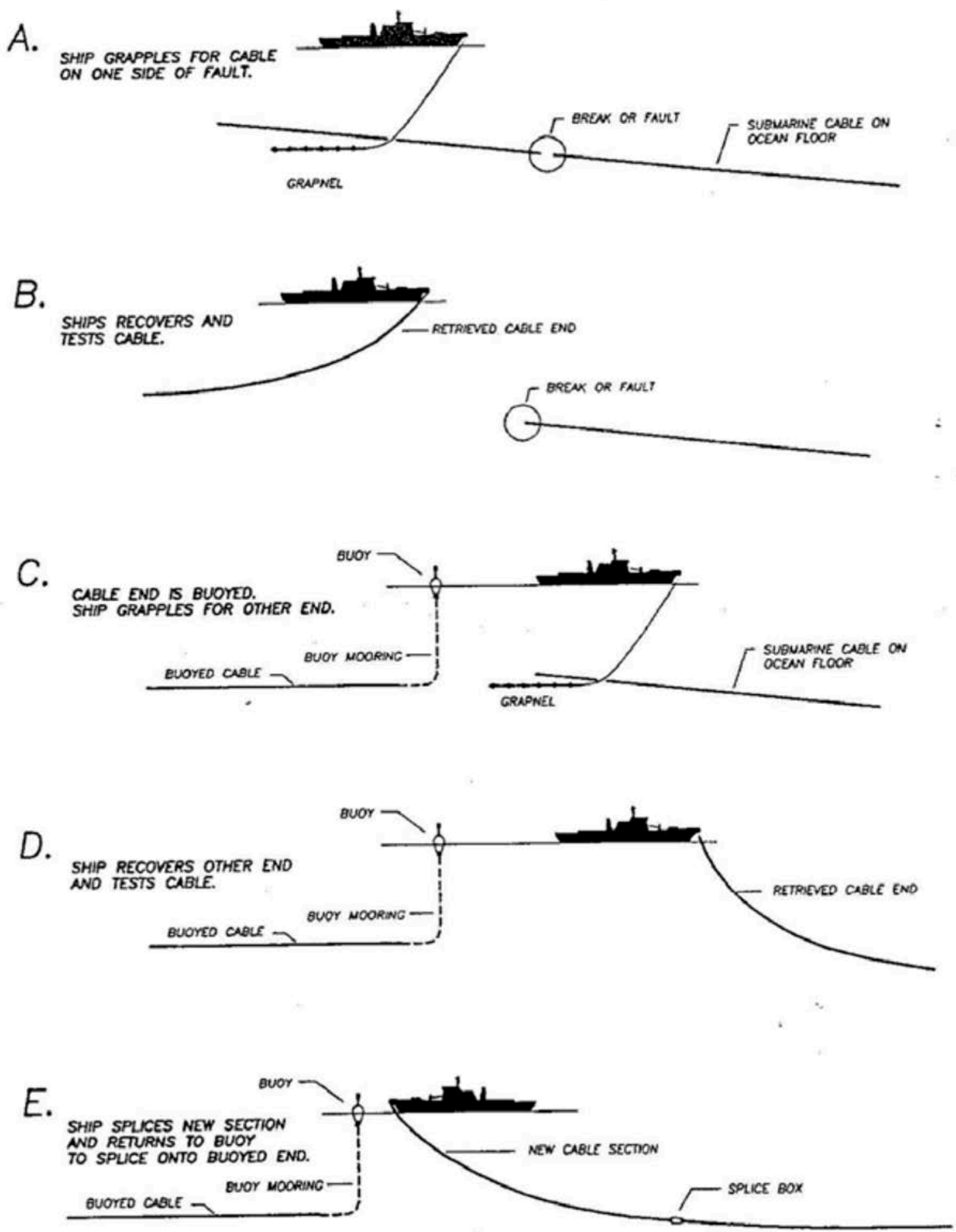

Figure 3. Ship operations for submarine cable repair (adapted from Communications Security, Reliability and Interoperability Council IV 2014)

Although submarine cable locations are accessible through several publicly available data sets and electronic navigation charts, a clear understanding of the areas where cable paths exist with 
respect to safe setback distances and the overlap with promising marine energy resources does not yet exist.

The Code of Federal Regulations (30 CFR § 585.301) does specify legal rights of way (ROW) and right-of-use and easement (RUE) specific to renewable energy activities for a 200-foot (ft) (61-meter $[\mathrm{m}])$ width spanning existing submarine cables:

\section{$30 \S 585.301$ What do ROW grants and RUE grants include?}

(a) An ROW grant:

(1) Includes the full length of the corridor on which a cable, pipeline, or associated facility is located;

(2) Is 200 feet (61 meters) in width, centered on the cable or pipeline, unless safety and environmental factors during construction and maintenance of the associated cable or pipeline require a greater width; and

(3) For the associated facility, is limited to the area reasonably necessary for a power or pumping station or other accessory facility.

(b) An RUE grant includes the site on which a facility or other structure is located and the areal extent of anchors, chains, and other equipment associated with a facility or other structure. The specific boundaries of an RUE will be determined by BOEM [Bureau of Ocean Energy Management] on a case-by-case basis and set forth in each RUE grant.

Although default separation distances for submarine cables that are not part of renewable energy activities have not been strictly and legally defined in the United States, the U.S. Coast Guard regularly establishes safety zones around facilities in the U.S. Outer Continental Shelf to a maximum of $500 \mathrm{~m} \mathrm{(33} \mathrm{CFR} \S 147.15)$.

A detailed analysis of the co-occurrence of other ocean uses or users (e.g., fishing, surfing, mining, sailing), is beyond the scope of this work. This work focuses on the cable industry to understand the specific areas of overlapping interest between cables and marine renewable energy, and to provide a high-quality data product that can be used in future marine spatial planning efforts that consider a more comprehensive collection of potential ocean uses. By applying cable-industry advised setback distances to existing cable routes, this work provides a marine planning product for identifying overlap between cable paths and other ocean uses including marine renewable energy. 


\section{Methods}

In this report, we apply cable-industry-advised, depth-varying setback distances to existing submarine cable routes. The resulting spatial product defines a footprint that indicates the area where the cable industry is an active stakeholder. This information can then be used to inform the planning of marine renewable energy project development. We further summarize the overlap of these safety setback areas with energy classes of theoretical resource potential for wave, wind, and tidal. In the spirit of reproducible research (Lowndes et al. 2017; Madeyski and Kitchenham 2015), all analytical code to generate results, including this data-driven report, are available in a publicly accessible online repository (http://github.com/ecoquants/nrel-cables).

This work uses an area-based geospatial analysis to maintain a consistent approach among resource types, which is relatively simple to implement and describe and is useful to marine renewable energy project developers and regulatory agencies because we provide maps of areas where cable operators are active stakeholders. This analysis does not, however, provide a definitive accounting of the "fraction of resource" (e.g., in units of terawatt-hours per year [TWh/yr]) that overlaps with cables. That result is beyond the scope of this work because there is no accepted method for quantifying wave or tidal technically recoverable resource totals. Proposed methods for doing so require either significant computational resources or manually selecting a subjectively defined and site-specific "resource integration contour." The area-based results presented herein, therefore, serve as a proxy for total-resource overlap estimates.

\subsection{Study Area, Submarine Cables, Depth, and Energy Data}

The study area consists of all waters (Flanders Marine Institute 2016) inside the 200-nauticalmile U.S. exclusive economic zone (EEZ). The United Nations Convention on the Law of the Sea specifically associates rights to renewable energy production within the EEZ (in bold) ${ }^{7}$ :

1. In the exclusive economic zone, the coastal State has:

(a) sovereign rights for the purpose of exploring and exploiting, conserving and managing the natural resources, whether living or non-living, of the waters superjacent to the seabed and of the seabed and its subsoil, and with regard to other activities for the economic exploitation and exploration of the zone, such as the production of energy from the water, currents and winds;

Cable routes were taken from the publicly available submarine cable data set "NOAA Charted Submarine Cables in the United States as of December 2012" available through MarineCadastre.gov. ${ }^{8} \mathrm{We}$ then divided this data set into the following regions: Alaska, Atlantic Islands (Puerto Rico, U.S. Virgin Islands), Hawaii, West Coast, East Coast, Gulf of Mexico, and Pacific Islands (Guam, Johnston Atoll, N. Mariana Islands, Palmyra Atoll, and Wake Island). The Gulf of Mexico region definition comes from the International Hydrographic Organization Sea Areas (VLIZ 2017). These 12 regions and the cable data set are depicted in Figure 4 and summarized by region in Table 1. Note some territories in Figure 4 have been grouped into the

\footnotetext{
7 “Article 56: Rights, jurisdiction and duties of the coastal State in the exclusive economic zone," United Nations Convention on the Law of the Sea Part V Exclusive Economic Zone:

http://www.un.org/depts/los/convention_agreements/texts/unclos/part5.htm.

${ }^{8}$ MarineCadastre.gov cable metadata: https://data.noaa.gov/dataset/dataset/noaa-charted-submarine-cables-in-theunited-states-as-of-december-2012.
} 
following regions: "Pacific Islands" includes Guam, Johnston Atoll, N. Mariana Islands, Palmyra Atoll, and Wake Island, and "Atlantic Islands" includes Puerto Rico and U.S. Virgin Islands.

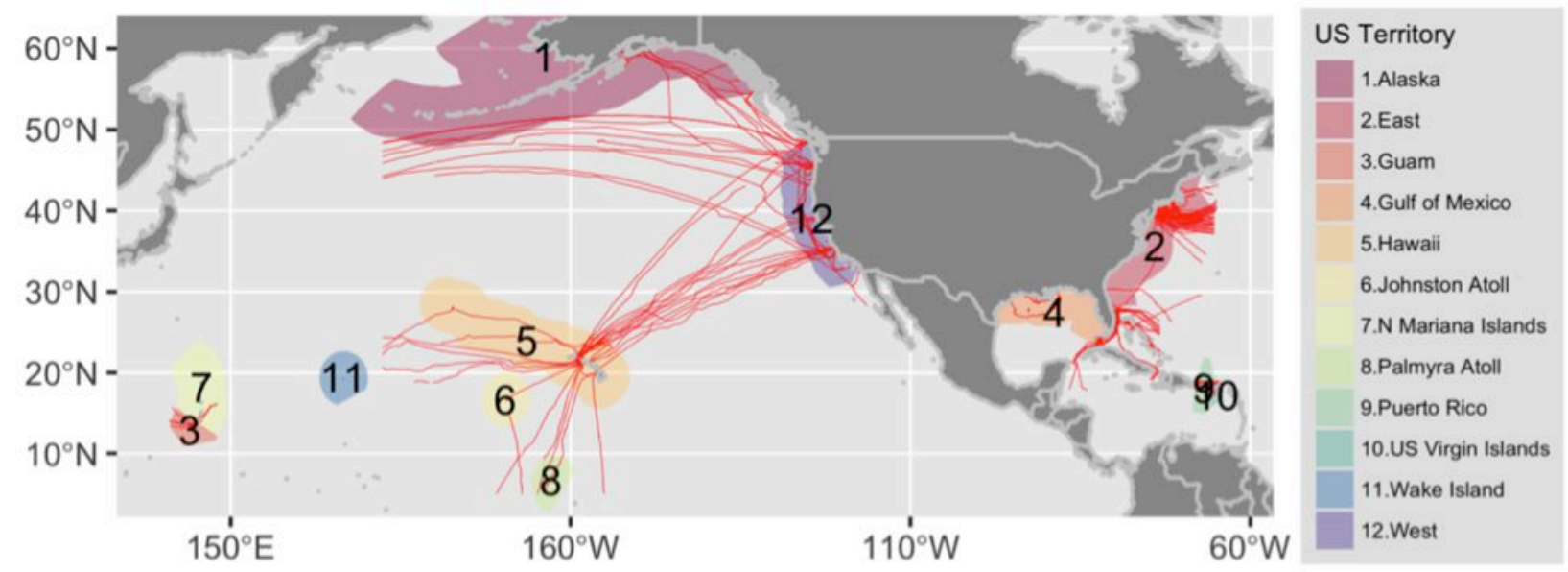

Figure 4. Map of National Oceanic and Atmospheric Administration charted submarine cables (red lines) and U.S. EEZ regions (colors)

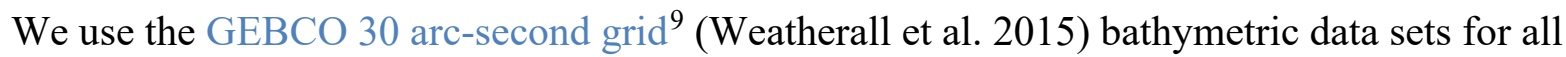
depth data. The marine renewable energy resource intensity data sets used in this report are accessible online via NREL's Wind Prospector ${ }^{10}$ and marine and hydrokinetic (MHK) Atlas. ${ }^{11}$ Tidal data were modeled using the Regional Ocean Modeling System and calibrated with available measurements of tidal current speed and water level surface in terms of watts per square meter $\left(\mathrm{W} / \mathrm{m}^{2}\right)$ (Haas et al. 2011). Wave data are based on a 51-month Wavewatch III hindcast database developed by the National Oceanographic and Atmospheric Administration's (NOAA's) National Centers for Environmental Prediction for estimation of wave power density in terms of kilowatts per meter $(\mathrm{kW} / \mathrm{m})$ (Jacobson et al. 2011). Wind data are for average offshore wind speed in meters per second $(\mathrm{m} / \mathrm{s})$ at a $90-\mathrm{m}$ hub height ${ }^{12}$ (Schwartz et al. 2010).

Throughout the tables in this work we utilize "visual indicators" (e.g., the black indicator bars in Table 1) to help interpret the data. In Table 1, the horizontal black bars within the "Region $\left(\mathrm{km}^{2}\right)$ " column indicate the regional fraction of the total U.S. EEZ area, and the horizontal black bars under the "Cable $(\mathrm{km})$ " indicate the regional fraction of cable length. Because energy resource data were not universally available, the last three columns indicate which resource data were available per region. In particular, note that Hawaii is missing tidal data because the tidal energy resource is small there, and wind energy data are unavailable for Alaska and the Atlantic Islands.

\footnotetext{
${ }^{9}$ GEBCO_2014 Grid, version 20150318, www.gebco.net

${ }^{10}$ NREL Wind Prospector: https://maps.nrel.gov/wind-prospector/

${ }^{11}$ NREL MHK Atlas: https://maps.nrel.gov/mhk-atlas

${ }^{12}$ Wind data for 90-meter offshore: https://www.nrel.gov/gis/data-wind.html
} 
Table 1. Summary of U.S. Regions Data, including EEZ Area, Cable Lengths, and Availability of Resource Data

\begin{tabular}{|c|c|c|c|c|c|}
\hline Region & Region $\left(\mathrm{km}^{2}\right)$ & Cable (km) & Tidal & Wave & Wind \\
\hline Alaska & $3,682,912$ & 15,782 & प & $\checkmark$ & \\
\hline Atlantic Islands & 211,232 & 4,241 & $\checkmark$ & $\checkmark$ & \\
\hline East & 932,351 & 28,526 & $\checkmark$ & $\checkmark$ & $\checkmark$ \\
\hline Gulf of Mexico & $1,553,288$ & 1,909 & $\checkmark$ & $\checkmark$ & $\checkmark$ \\
\hline Hawaii & $2,474,715$ & 21,496 & & $\checkmark$ & $\checkmark$ \\
\hline Pacific Islands & $2,174,943$ & 4,908 & & & \\
\hline West & 824,679 & 20,459 & $\checkmark$ & $\checkmark$ & $\checkmark$ \\
\hline ALL & $11,854,120$ & 97,321 & $\checkmark$ & $\checkmark$ & $\checkmark$ \\
\hline
\end{tabular}

\subsection{Cable-Industry-Advised Submarine Cable Avoidance Zones}

The International Cable Protection Committee (ICPC) ${ }^{13}$ of the North American Submarine Cable Association (NASCA) ${ }^{14}$ recommended setback distances (Communications Security, Reliability and Interoperability Council IV 2014, 2016) for siting new offshore renewable wind energy facilities and routing new cables. Those recommended setback distances (i.e., horizontal buffers to either side of cable paths) were:

- New Facilities. The maximum of $500 \mathrm{~m}$ or twice the bottom depth (2z), per ICPC Recommendation 13 No. 2 (Communications Security, Reliability and Interoperability Council IV 2014). For depths $<=250 \mathrm{~m}$, a 500-m buffer from the cables applies and for depths $>250 \mathrm{~m}, 2 *$ depth is to be used. This cable setback product is also referred to as the "new facilities $(2 \mathrm{z})$ " product in this report.

- New Cables. The maximum of $500 \mathrm{~m}$ or three times the bottom depth (3z), per ICPC Recommendation 2 No. 10 (Communications Security, Reliability and Interoperability Council IV 2014). So for depths $<=167 \mathrm{~m}$, a 500-m buffer from the cables applies and for depths $>167 \mathrm{~m}, 3 *$ depth is to be used. This cable setback product is referred to as the "new cables $(3 \mathrm{z})$ " product in this report.

Although both recommendations were implemented into separate setback area products, the "Cable Setback Area" used throughout the rest of the report refers to the maximum area (i.e., the cables $(3 z)$ product). The new facilities $(2 z)$ setback product is roughly two-thirds of the area of the new cables (3z) setback product; therefore, we focus on the more conservative $3 \mathrm{z}$ results. The data layers for the $100-\mathrm{ft}, 2 \mathrm{z}$, and $3 \mathrm{z}$ cable-setback areas are publicly available in the MHK Data Repository (OpenEI 2019)).

${ }^{13}$ International Cable Protection Committee: https://www.iscpc.org

${ }^{14}$ North American Submarine Cable Association: https://www.n-a-s-c-a.org 


\subsection{Depth-Varying Cable Buffer}

We calculated the cable setback area for the previously mentioned recommendations by combining depth data with cable path data and buffering the cable segment by the depth multiplier (Figure 5). Submarine cables follow the seafloor (green lines) and are indicated at the surface (red lines). The bottom depth ( $\mathrm{z}$ ) is then multiplied by two to describe the horizontal setback area for new marine renewable energy facilities ( $2 z$; dark red polygon) and by three for new cables (3z; light red polygon). As depth increases, the safety buffer widens. A custom Albers Equal Area Conic projection based on one-sixth of the extent ${ }^{15}$ of each region was individually applied to minimize spatial distortion when buffering. Throughout the remainder of this work we use the $3 z$ layer to identify locations where cable operators are active stakeholders.

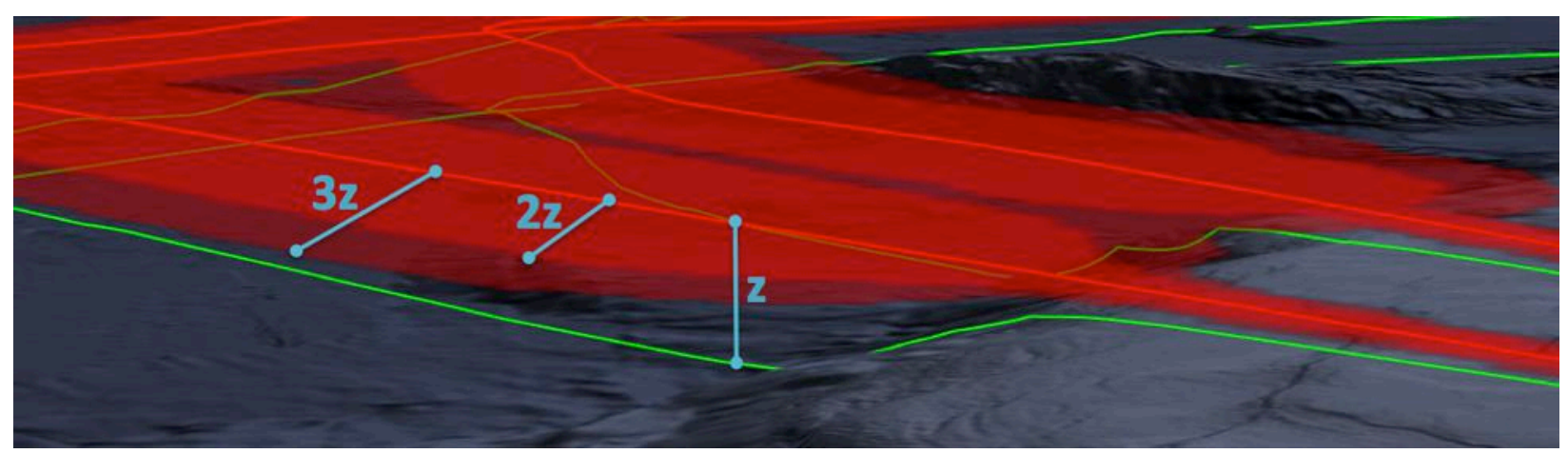

Figure 5. Oblique angle view of cable setback definitions

\footnotetext{
15 The "one-sixth rule" for Albers Equal Area Conic projection: http://desktop.arcgis.com/en/arcmap/latest/map/projections/albers-equal-area-conic.htm\#GUID-2158C4F9-F197- 


\section{Results}

The results contained herein provide a summary of the overlap between submarine cable setbacks and viable marine energy resource areas. These results are based on the latest data available at the time of writing this report (2018) for both cable routes, and marine energy resources. The results do not account for the "probability" or "desirability" of a marine energy site. Instead, viability is defined only based on the intensity of the marine renewable energy resource at the site, and the filter thresholds are defined according to existing grid-scale marine renewable energy technologies. In other words, as: a) cable routes are added and removed, b) data on marine renewable energy resources are refined, and c) marine renewable energy technologies evolve (e.g., technologies designed to power the blue economy), the results presented in the following sections may change considerably.

\subsection{Cable Buffer}

Of the original $230,835 \mathrm{~km}$ of cable in the cable data set (Figure 4), 97,321 km fell within the 200-nautical-mile U.S. EEZ, which was analyzed across 12 regions that overlapped with the cables (Figure 4). The cable buffer area ranged from $29.3 \%\left(242,031 \mathrm{~km}^{2}\right.$ of $824,679 \mathrm{~km}^{2}$ total) in the West, owing to the presence of many cables in the relatively deep waters offshore of the narrow continental shelf, to nearly zero $\left(0.6 \%\right.$ or $9,211 \mathrm{~km}^{2}$ of $1,553,288 \mathrm{~km}^{2}$ total $)$ in the Gulf of Mexico (Table 2). In Table 2, the horizontal black bar under Area indicates the percent area relative to total area of the U.S. EEZ (gray bar background), and the black bar under the Cable Setback Area indicates the percent of that region's available area that overlaps with cable setbacks.

Table 2. Area of Regions and Advisory Cable Setback Within the EEZ

\begin{tabular}{|c|c|c|}
\hline Region & Area $\left(\mathbf{k m}^{2}\right)$ & $3 z$ Cable Setback Area $\left(\mathrm{km}^{2}\right)(\%)$ \\
\hline Alaska & $3,682,912$ & $237,610 \quad(6.5 \%)$ \\
\hline Atlantic Islands & 211,232 & $43,043 \quad(20.4 \%)$ \\
\hline East & 932,351 & $165,004 \quad(17.7 \%)$ \\
\hline Gulf of Mexico & $1,553,288$ & $9,211(0.6 \%)$ \\
\hline Hawaii & $2,474,715$ & $419,341 \quad(16.9 \%)$ \\
\hline Pacific Islands & $2,174,943$ & $151,849(7.0 \%)$ \\
\hline West & 824,679 & $242,031 \quad(29.3 \%)$ \\
\hline ALL & $11,854,120$ & $1,268,089 \quad(10.7 \%)$ \\
\hline
\end{tabular}

\subsection{Overlap of Cable Buffer with Renewable Energy}

Overlap of the $3 z$ cable buffer with marine renewable energy was assessed for tidal (Haas et al. 2011), wave (Jacobson et al. 2011), and wind (Schwartz et al. 2010) energy based on energy resource characterizations available through NREL's Wind Prospector and MHK Atlas. Assessment of overlap with the advised separation schemes and energy resource was limited to maximum depths based on a current assessment of technology limitations: $\leq 100 \mathrm{~m}$ for tidal (Kilcher et al. 2016; Haas et al. 2011), $\leq 200 \mathrm{~m}$ for wave (Kilcher and Thresher 2016; Jacobson et al. 2011), $\leq 1,000 \mathrm{~m}$ for wind (Musial et al. 2016). 
The lowest energy classes were also dropped from the assessment, thereby yielding the following evaluated "viable" bins of resource intensity:

- $\quad$ Tidal (W/m ${ }^{2}$ at $\leq 100-\mathrm{m}$ depth): $50-1,000,1,000-1,500,>1,500$

- Wave (kW/m at $\leq 200-\mathrm{m}$ depth): 10-20, 20-30, $>30$

- $\quad$ Wind (m/s at $\leq 1,000-\mathrm{m}$ depth): 7-8, 8-9, 9-10, 10-11, 11-12.

Overall (the first three rows of Table 3), the total area of viable tidal resource $\left(1,671 \mathrm{~km}^{2}\right)$ is more than two orders of magnitude smaller than wave $\left(378,908 \mathrm{~km}^{2}\right)$ or wind $\left(462,613 \mathrm{~km}^{2}\right)$, owing to far fewer locations that concentrate tidal flux for sufficient energy generation (Haas et al. 2011). Nationally, tidal energy has up to a $3.8 \%$ overlap, wave $(0.9 \%)$, and wind (4\%) (Table 3 ), so overlap between the viable marine renewable energy resource and existing submarine cables is generally minimal. In Table 3, black bars under Area indicate size of area relative to the maximum $\left(462,000 \mathrm{~km}^{2}\right)$, and black bars under Cable Setback Area indicate the percentage of area in that resource category (depth and resource bin) that overlaps with cable setbacks.

Table 3. Area of Energy and Depth Classes with Advisory 3z Cable Setback Overlap; Across All Assessed Energy Resources

\begin{tabular}{|c|c|c|c|c|c|c|}
\hline Form & Energy & $\begin{array}{l}\text { Depth } \\
(\mathrm{m})\end{array}$ & Area $\left(\mathrm{km}^{2}\right)$ & \multicolumn{3}{|c|}{$\begin{array}{c}\text { 3z Cable Setback } \\
\text { Area }\left(\mathrm{km}^{2}\right)(\%)\end{array}$} \\
\hline Tidal $\left(\mathrm{W} / \mathrm{m}^{2}\right)$ & ALL & ALL & 1,671 & I & 63 & $(3.8 \%)$ \\
\hline $\begin{array}{l}\text { Wave } \\
(\mathrm{kW} / \mathrm{m})\end{array}$ & ALL & ALL & 378,908 & I & 3,352 & $(0.9 \%)$ \\
\hline Wind $(\mathrm{m} / \mathrm{s})$ & ALL & ALL & 462,613 & I & 18,481 & $(4.0 \%)$ \\
\hline \multirow[t]{3}{*}{ Tidal $\left(\mathrm{W} / \mathrm{m}^{2}\right)$} & $500-1,000$ & $0-100$ & 1,160 & I & 54 & $(4.7 \%)$ \\
\hline & $1,000-1,500$ & $0-100$ & 306 & 1 & 7 & $(2.3 \%)$ \\
\hline & $>1,500$ & 0100 & 205 & I & 2 & $(0.9 \%)$ \\
\hline \multirow{6}{*}{$\begin{array}{l}\text { Wave } \\
(\mathrm{kW} / \mathrm{m})\end{array}$} & $10-20$ & $0-100$ & 121,861 & I & 831 & $(0.7 \%)$ \\
\hline & & $100-200$ & 47,416 & I & 925 & $(2.0 \%)$ \\
\hline & 20-30 & $0-100$ & 62,767 & L & 170 & $(0.3 \%)$ \\
\hline & & $100-200$ & 77,833 & 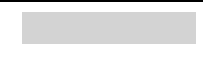 & 327 & $(0.4 \%)$ \\
\hline & $>30$ & $0-100$ & 21,213 & I & 332 & $(1.6 \%)$ \\
\hline & & $100-200$ & 47,818 & I & 767 & $(1.6 \%)$ \\
\hline Wind $(\mathrm{m} / \mathrm{s})$ & $7-8$ & $0-100$ & 134,633 & I & 1,756 & $(1.3 \%)$ \\
\hline
\end{tabular}




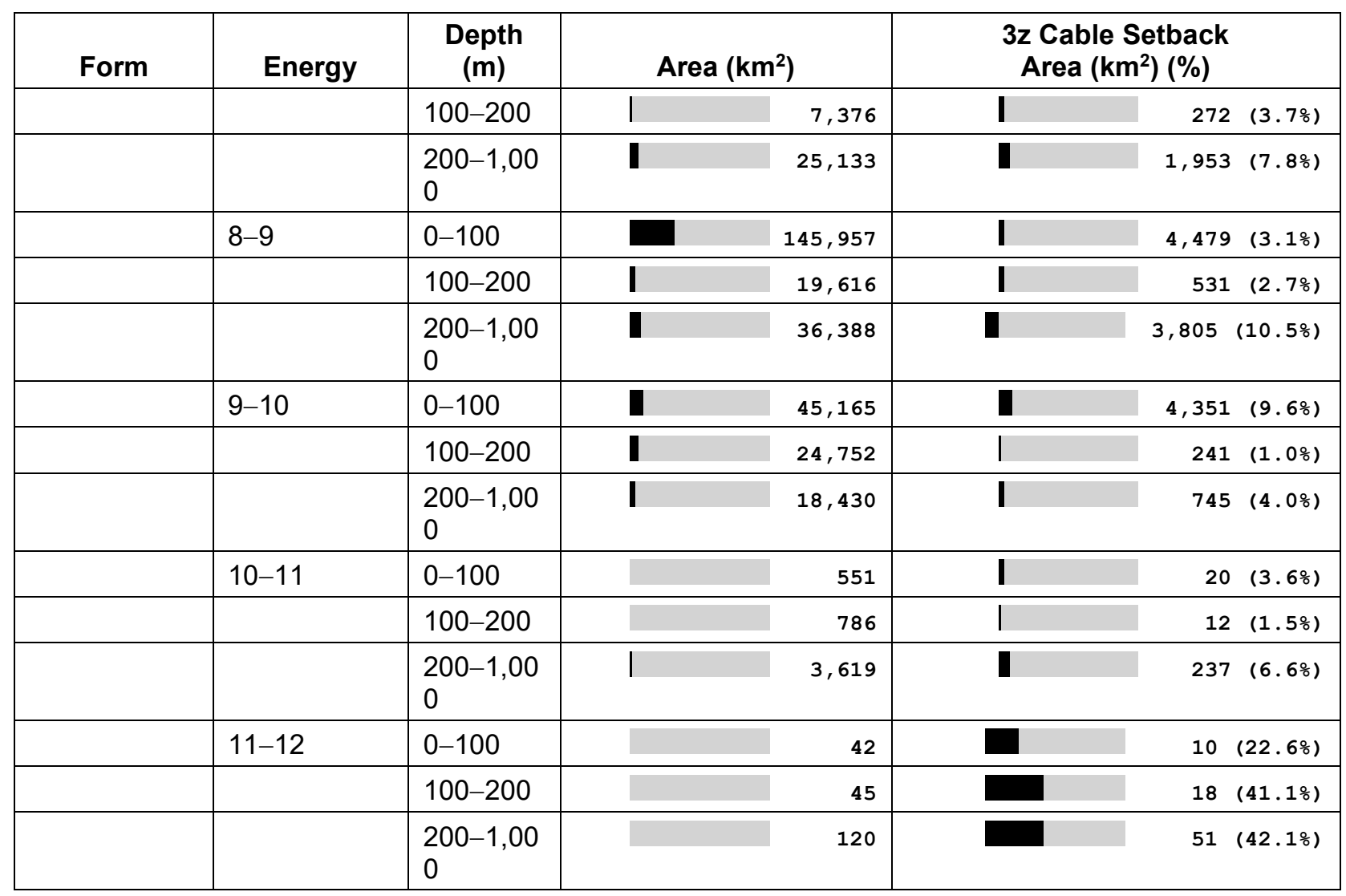

\subsubsection{Tidal}

Viable tidal resource (Table 3 ) has $4.7 \%$ overlap for the lowest energy class $\left(500-1,000 \mathrm{~W} / \mathrm{m}^{2}\right)$, with only $2.3 \%$ and $0.9 \%$ overlap at higher power classes $1,000-1,500$ and $>1,500 \mathrm{~W} / \mathrm{m}^{2}$, respectively. Availability of tidal energy resource and overlap with cable buffer varies across regions (Table 4). In Table 4, the viable area only includes areas where water depth is $\leq 100 \mathrm{~m}$. The "ALL" category for each region indicates the area where resource intensity is $\geq 500 \mathrm{~W} / \mathrm{m}^{2}$. Black bars under Area indicate area relative to the maximum for each region and category, and black bars under Cable Setback Area indicate the percent of the resource that overlaps with cable setbacks. The Atlantic Islands (Puerto Rico, U.S. Virgin Islands) did not have sites with $>500$ $\mathrm{W} / \mathrm{m}^{2}$; therefore, they do not show up in this table.

Viable tidal power area is most abundant in Alaska $\left(954 \mathrm{~km}^{2}\right)$, then the East $\left(604 \mathrm{~km}^{2}\right)$, the West $\left(69 \mathrm{~km}^{2}\right)$, and finally the Gulf of Mexico $\left(43 \mathrm{~km}^{2}\right)$. Tidal energy was only considered up to a maximum depth of $100 \mathrm{~m}$, so only the minimum 500-m horizontal separation scheme was applicable for any area overlapping with submarine cables. 
Table 4. Viable Tidal Resource Area and Advisory Setbacks by Region and Resource Bin

\begin{tabular}{|c|c|c|c|}
\hline Region & Tidal Power $\left(\mathrm{W} / \mathrm{m}^{2}\right)$ & Area $\left(\mathrm{km}^{2}\right)$ & $3 z$ Cable Setback Area $\left(\mathrm{km}^{2}\right)(\%)$ \\
\hline \multirow[t]{4}{*}{ Alaska } & ALL & 955 & \begin{tabular}{l|l|l} 
I & $41 \quad(4.3 \%)$
\end{tabular} \\
\hline & $500-1,000$ & 691 & $33(4.8 \%)$ \\
\hline & $1,000-1,500$ & 162 & $1 \quad 5(3.3 \%)$ \\
\hline & $>1,500$ & 101 & $2(1.8 \%)$ \\
\hline \multirow[t]{4}{*}{ East } & ALL & 604 & $8(1.3 \%)$ \\
\hline & $500-1,000$ & 390 & $6(1.7 \%)$ \\
\hline & $1,000-1,500$ & 127 & $2(1.3 \%)$ \\
\hline & $>1,500$ & 87 & $0(0.0 \%)$ \\
\hline \multirow[t]{4}{*}{ Gulf of Mexico } & ALL & 43 & $0(0.0 \%)$ \\
\hline & $500-1,000$ & 32 & $0(0.0 \%)$ \\
\hline & $1,000-1,500$ & 8 & $0(0.0 \%)$ \\
\hline & $>1,500$ & 3 & $0(0.0 \%)$ \\
\hline \multirow[t]{4}{*}{ West } & ALL & 69 & $14(20.8 \%)$ \\
\hline & $500-1,000$ & 46 & 14 (31.5\%) \\
\hline & $1,000-1,500$ & 9 & $0(0.0 \%)$ \\
\hline & $>1,500$ & 14 & $0(0.0 \%)$ \\
\hline
\end{tabular}

In Alaska, where tidal energy is the most abundant, the lowest tidal energy class (500-1,000 $\mathrm{W} / \mathrm{m}^{2}$ ) overlapped only up to $4.8 \%$ (Table 4 ). Inspecting higher energy areas, such as Cook Inlet (Figure 6), overlap with submarine cables is visible but relatively minimal because of the presence of only a few cables and the shallow bottom depth there. 


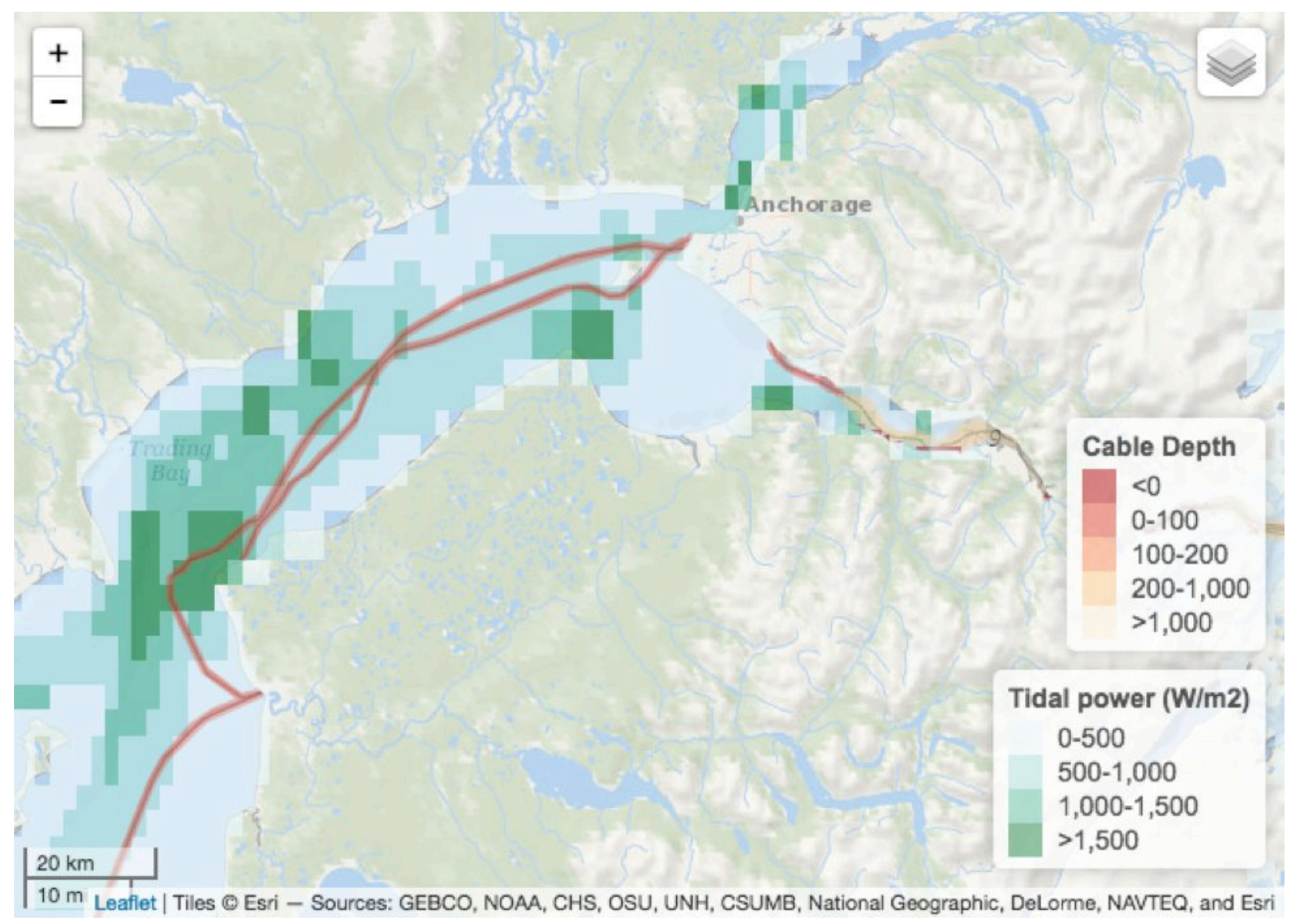

Figure 6. Map of tidal energy resource intensity (green) and advisory $3 z$ cable setbacks (red) in Cook Inlet, Alaska. The background contextual map layer is provided by Esri (2019)

There is a particularly high (31.5\%) overlap in the West region at the lowest viable power bin $\left(500-1,000 \mathrm{~W} / \mathrm{m}^{2}\right)$. The majority of this overlap is in Admiralty Inlet, at the entrance to Puget Sound, where a cable route passes through the inlet (Figure 7). Notably, other sites in the Puget Sound subregion have higher resource intensity and do not have the presence of cables. Furthermore, measurements from the Admiralty Inlet site indicate that models used in this analysis underpredict the resource (Thomson et al. 2012). The measurements suggest that the resource in Admiralty Inlet is $>1,000 \mathrm{~W} / \mathrm{m}^{2}$, and therefore the overlap between valuable marine renewable energy resources with cable setbacks is potentially more significant than otherwise indicated here. This is one example of how refined resource data may change the picture of the overlap between these ocean uses. 


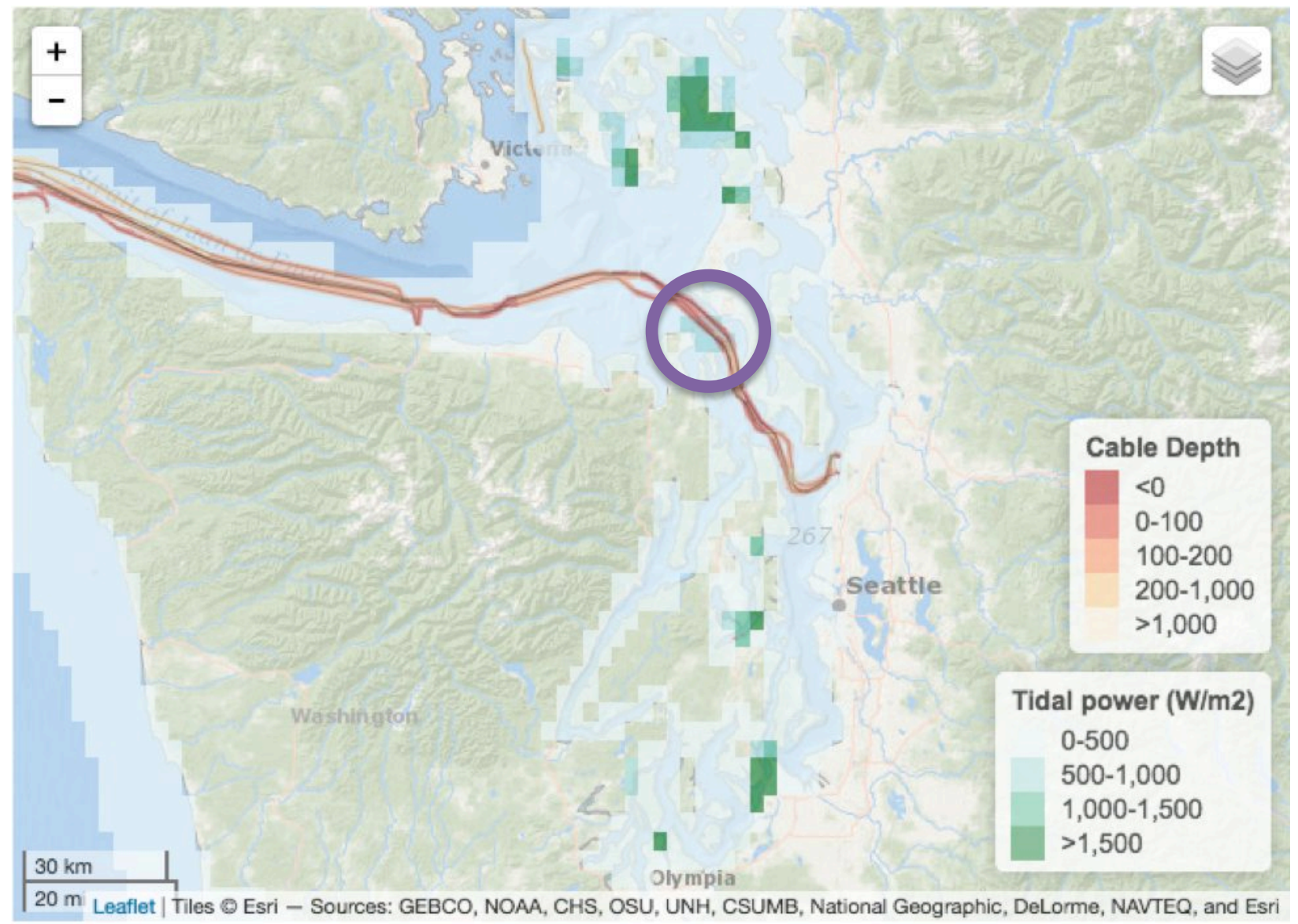

Figure 7. Tidal energy resource intensity (green) and advisory $3 z$ cable setbacks (red) in the Puget Sound area; the purple circle is centered on Admiralty Inlet. The background contextual map layer is provided by Esri (2019)

\subsubsection{Wave}

Nationally, wave energy at either depth bin of $0-100$ or $100-200 \mathrm{~m}$ is very low, having a2\% overlap at most with cable setbacks for the lower energy class (10-20 kW/m) at depths between 100 and $200 \mathrm{~m}$ (Table 3). The availability of wave energy resource varies between regions (Table 5). The viable resource area for each resource category is indicated in the Area column by black bars, and the percentage of that area that overlaps with cable setbacks is indicated by black bars in the Cable Setback Area column. The "ALL" category for each region is limited to depths $\leq$ $200 \mathrm{~m}$ and resource intensity $\geq 10 \mathrm{~kW} / \mathrm{m}$. The Atlantic Islands (Puerto Rico and U.S. Virgin Islands) and Gulf of Mexico did not have areas that obey these criteria and therefore do not show up in this table.

Viable wave energy area is most abundant in Alaska, owing to high resource intensity, a long coastline, and a wide continental shelf. It also has a very small percent setback area $(0.4 \%)$. The West Coast has the second highest viable area because of the high resource intensity of the region. The East Coast has a wide continental shelf, but large portions of it fall below the 10 $\mathrm{kW} / \mathrm{m}$ resource intensity threshold; therefore, it follows the West Coast in viable resource area. The Hawaiian resource area is relatively small because of deep waters and a relatively short coastline. 
The setback percent areas vary from $0 \%$ to $<4 \%$ across all regions and resource categories. Alaska and Hawaii, in particular, have a very low cable setback percent area. In Alaska, this is because there are relatively few cables in the region (Figure 8 shows an area of the state with the highest cable density). In Hawaii, this is because most cables are on the south side of the islands, yet the wave resource is to the north of them. The East and West Coast setback percent areas are somewhat higher because of the presence of many cables (and the relatively narrow continental shelf in the west (e.g., Figure 9), but still cable setbacks occupy only a small fraction of the total viable area $(<4 \%)$. This small fraction indicates that there is relatively minimal overlap with the wave energy resource, especially when considering that a wave farm adjacent to a cable setback area can still capture the wave energy that propagates through the setback area to the farm.

Table 5. Viable Wave Resource Area and Advisory Setbacks by Region and Resource Category

\begin{tabular}{|c|c|c|c|}
\hline Region & Wave Energy (kW/m) & Area $\left(\mathrm{km}^{2}\right)$ & $3 z$ Cable Setback Area $\left(\mathrm{km}^{2}\right)(\%)$ \\
\hline \multirow[t]{4}{*}{ Alaska } & ALL & 312,374 & $1,298 \quad\left(0.4 \frac{\circ}{\circ}\right)$ \\
\hline & $10-20$ & 146,572 & $1,032 \quad(0.7 \%)$ \\
\hline & $20-30$ & 129,680 & $246(0.2 \%)$ \\
\hline & $>30$ & 36,122 & $20(0.1 \%)$ \\
\hline \multirow[t]{2}{*}{ East } & ALL & 16,463 & $536(3.3 \%)$ \\
\hline & $10-20$ & 16,463 & $536(3.3 \%)$ \\
\hline \multirow[t]{3}{*}{ Hawaii } & ALL & 1,915 & $21(1.1 \%)$ \\
\hline & $10-20$ & 1,604 & $21(1.3 \%)$ \\
\hline & $20-30$ & 311 & $0 \quad(0.0 \%)$ \\
\hline \multirow[t]{4}{*}{ West } & ALL & 48,155 & $1,498 \quad(3.1 \%)$ \\
\hline & $10-20$ & 4,637 & $168(3.6 \%)$ \\
\hline & $20-30$ & 10,608 & $251(2.4 \%)$ \\
\hline & $>30$ & 32,910 & $1,079 \quad(3.3 \%)$ \\
\hline
\end{tabular}




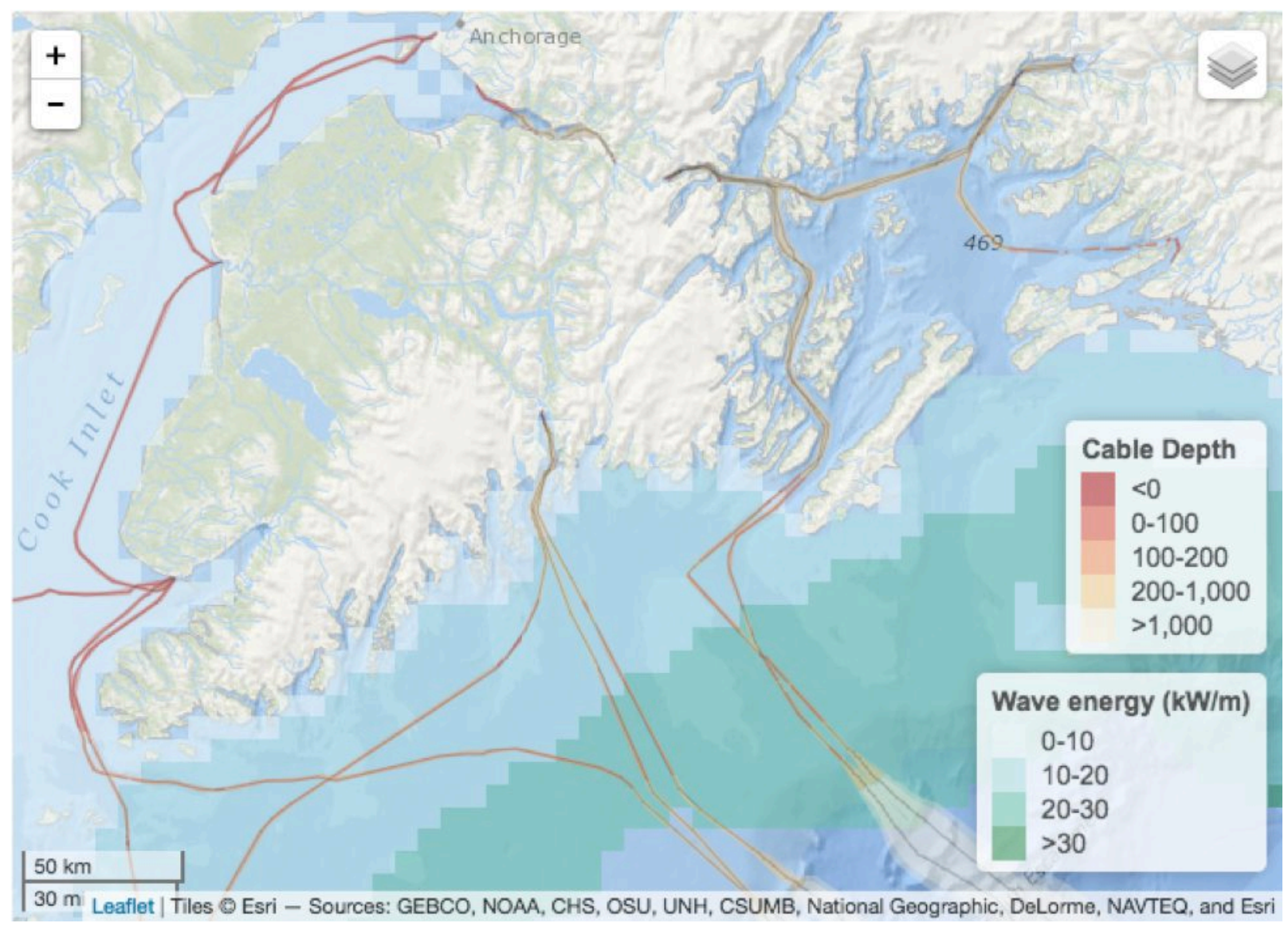

Figure 8. Viable wave energy area (green) and advisory $3 z$ cable setbacks (red) in the Cook Inlet, Alaska subregion. The background contextual map layer is provided by Esri (2019) 


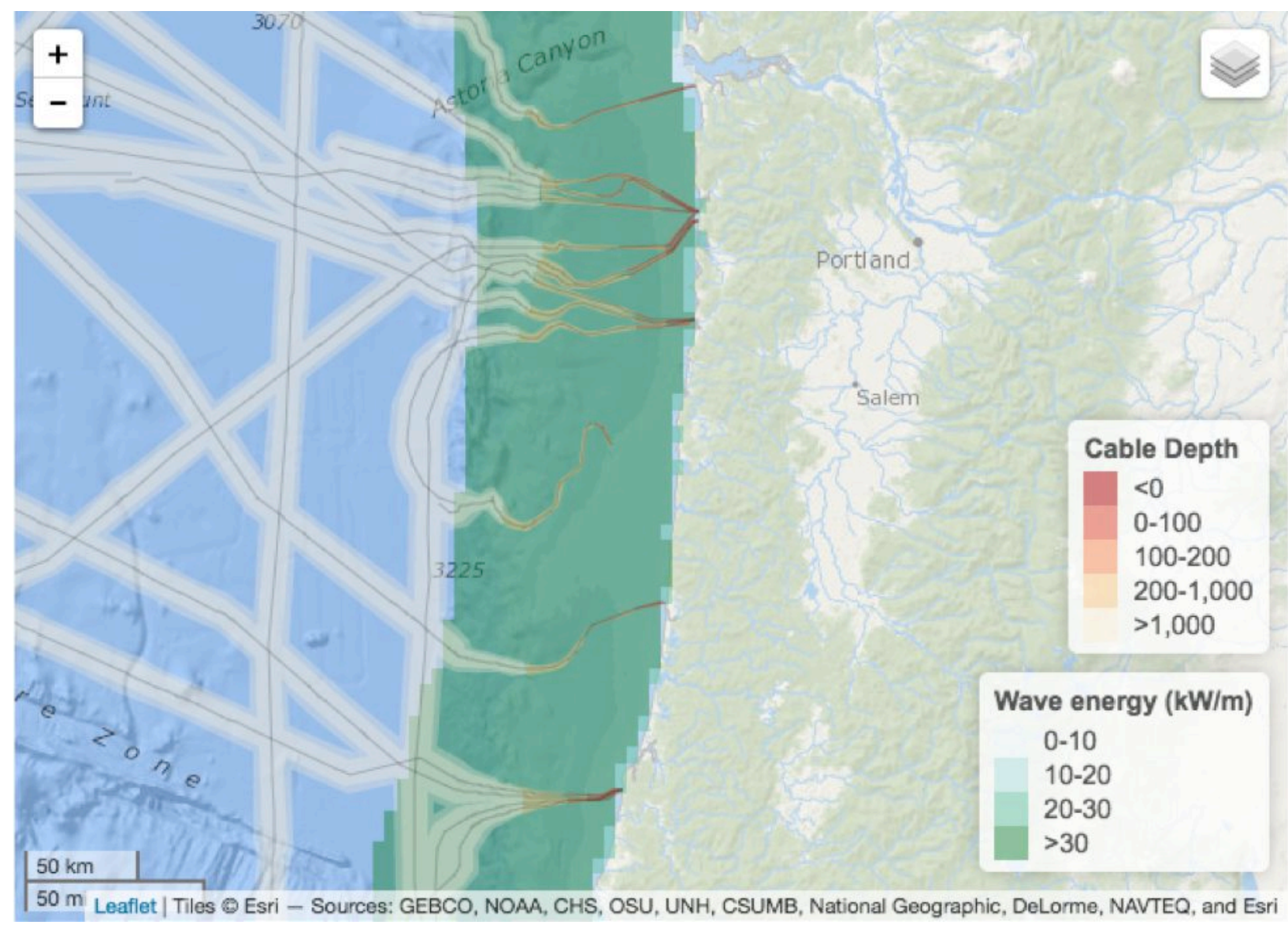

Figure 9. Viable wave energy area (green) and advisory $3 z$ cable setbacks (red) along the Oregon coast. The background contextual map layer is provided by Esri Wind (2019)

Nationally (Table 3), the most abundant viable wind in shallow depth (0-100 m) and lower energy (7-8 and 8-9 m/s) overlaps at 3.1\% at most, and overlaps more at higher speeds $(9.6 \%$ at $9-10 \mathrm{~m} / \mathrm{s})$ and in deeper waters $(7.8 \%$ and $10.5 \%$ at $7-8$ and $8-9 \mathrm{~m} / \mathrm{s}$, respectively, in depths of $200-1,000 \mathrm{~m})$. For the small area $\left(207 \mathrm{~km}^{2}\right)$ of highest wind speeds $(11-12 \mathrm{~m} / \mathrm{s})$, which occurs in Hawaii, overlap is up to $37.9 \%$ (Table 6).

For the regions assessed for wind energy (Table 1), viable wind is most abundant (Table 6) in the East Coast $\left(237,910 \mathrm{~km}^{2}\right)$, Gulf of Mexico $\left(113,562 \mathrm{~km}^{2}\right)$, West Coast $\left(94,488 \mathrm{~km}^{2}\right)$, and finally Hawaii $\left(16,654 \mathrm{~km}^{2}\right)$. In Table 6, as for the wave and tidal tables, black bars under the Area column indicate total area of the resource category, and black bars under Cable Setback Area indicate the fraction of that area that overlaps with cable setbacks. Alaska and Atlantic Islands are not included because resource data were not available at the time of this analysis. The maximum depth considered for viable wind energy areas is 1,000 m, much deeper than maximum depths for tidal $(100 \mathrm{~m})$ or wave $(200 \mathrm{~m})$. The only region to exceed $8 \%$ (Table 6$)$ in overlap with the cable separation scheme is Hawaii, where overlap is $37.9 \%$ for the highest wind energy class of $11-12 \mathrm{~m} / \mathrm{s}$.

When comparing maps of wind energy and submarine cable buffers between Hawaii (Figure 10) and the East Coast (Figure 11), bathymetry clearly plays a big role in the degree of difference in overlap (e.g., up to $3.6 \%$ for East and $19.8 \%$ for Hawaii in the $8-9 \mathrm{~m} / \mathrm{s} \mathrm{bin}$ ). Submarine cables prominently co-occur with viable wind energy in both locations; however, in Hawaii this cooccurrence is in deeper water where the submarine cable safety setback distance becomes larger. 
In contrast, the East Coast has a shallow continental shelf that extends to the offshore limits of the characterized wind energy resource.

Table 6. Viable Wind Resource Area and Advisory Setbacks by Region and Resource Category

\begin{tabular}{|c|c|c|c|}
\hline Region & Wind Speed $(\mathrm{m} / \mathrm{s})$ & Area $\left(\mathrm{km}^{2}\right)$ & $3 z$ Cable Setback Area $\left(\mathrm{km}^{2}\right)(\%)$ \\
\hline \multirow[t]{5}{*}{ East } & ALL & 237,909 & $\begin{array}{ccc}\text { I } & 9,290(3.9 \%)\end{array}$ \\
\hline & $7-8$ & 47,001 & $343(0.7 \%)$ \\
\hline & $8-9$ & 116,082 & $4,198 \quad(3.6 \%)$ \\
\hline & $9-10$ & 74,826 & $4,749 \quad(6.3 \%)$ \\
\hline & $10-11$ & 1 & $0(0.0 \%)$ \\
\hline \multirow[t]{3}{*}{ Gulf of Mexico } & ALL & 113,562 & 1,102 (1.0\%) \\
\hline & $7-8$ & 85,032 & $1,102 \quad(1.3 \%)$ \\
\hline & $8-9$ & 28,530 & $0 \quad(0.0 \%)$ \\
\hline \multirow[t]{6}{*}{ Hawaii } & ALL & 16,654 & $2,337(14.0 \%)$ \\
\hline & $7-8$ & 6,931 & $362 \quad(5.2 \%)$ \\
\hline & $8-9$ & 7,178 & $1,421(19.8 \%)$ \\
\hline & $9-10$ & 1,329 & $206(15.5 \%)$ \\
\hline & $10-11$ & 1,009 & $269(26.7 \%)$ \\
\hline & $11-12$ & 207 & $78 \quad(37.9 \%)$ \\
\hline \multirow[t]{5}{*}{ West } & ALL & 94,488 & $5,752(6.1 \%)$ \\
\hline & $7-8$ & 28,178 & $2,175 \quad(7.7 \%)$ \\
\hline & $8-9$ & 50,171 & $3,197 \quad(6.4 \%)$ \\
\hline & $9-10$ & 12,192 & $380(3.1 \%)$ \\
\hline & $10-11$ & | & $0(0.0 \%)$ \\
\hline
\end{tabular}




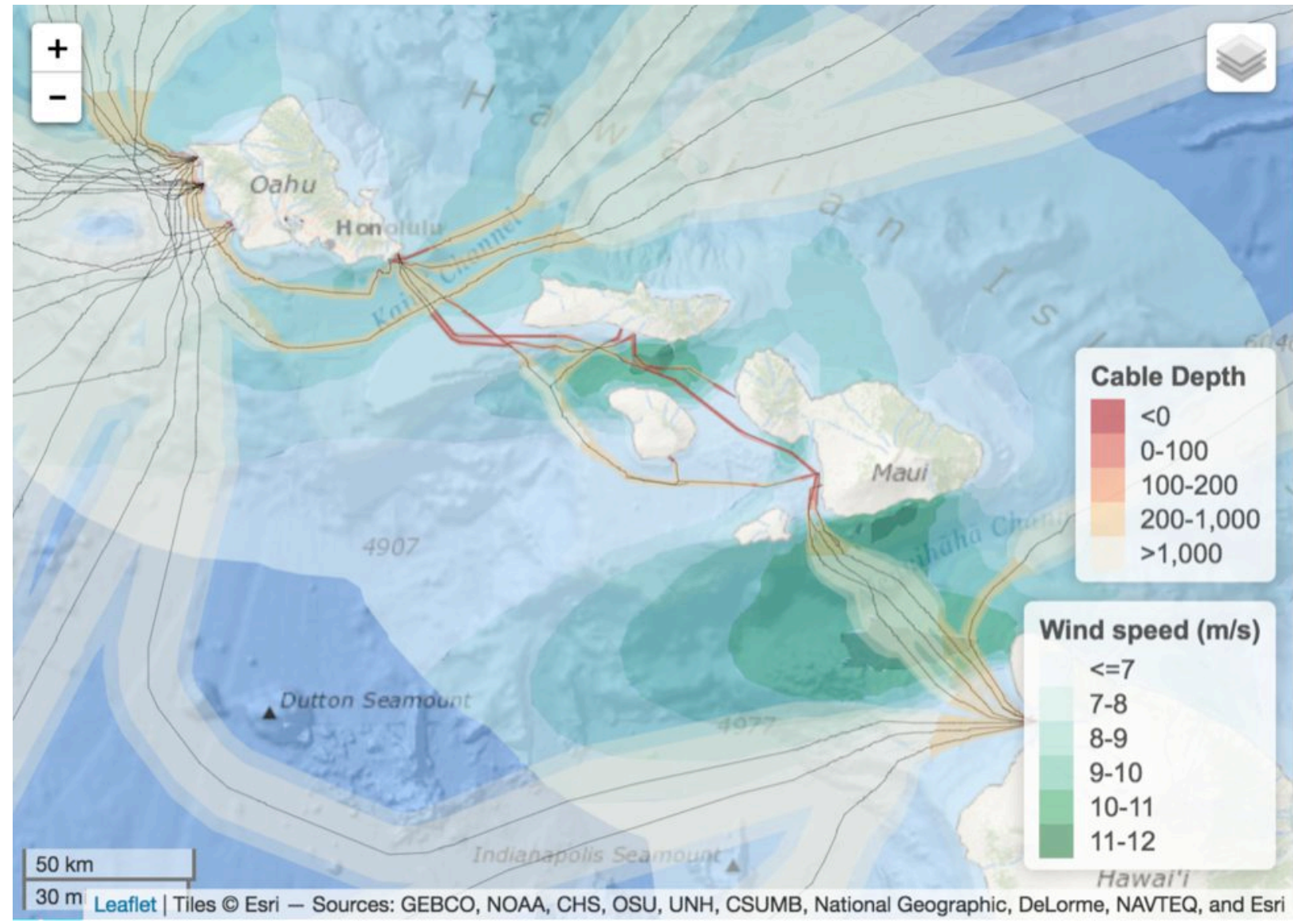

Figure 10. Viable offshore wind energy area (green) and advisory $3 z$ cable setbacks (red) in Hawaii. The background contextual map layer is provided by Esri (2019) 


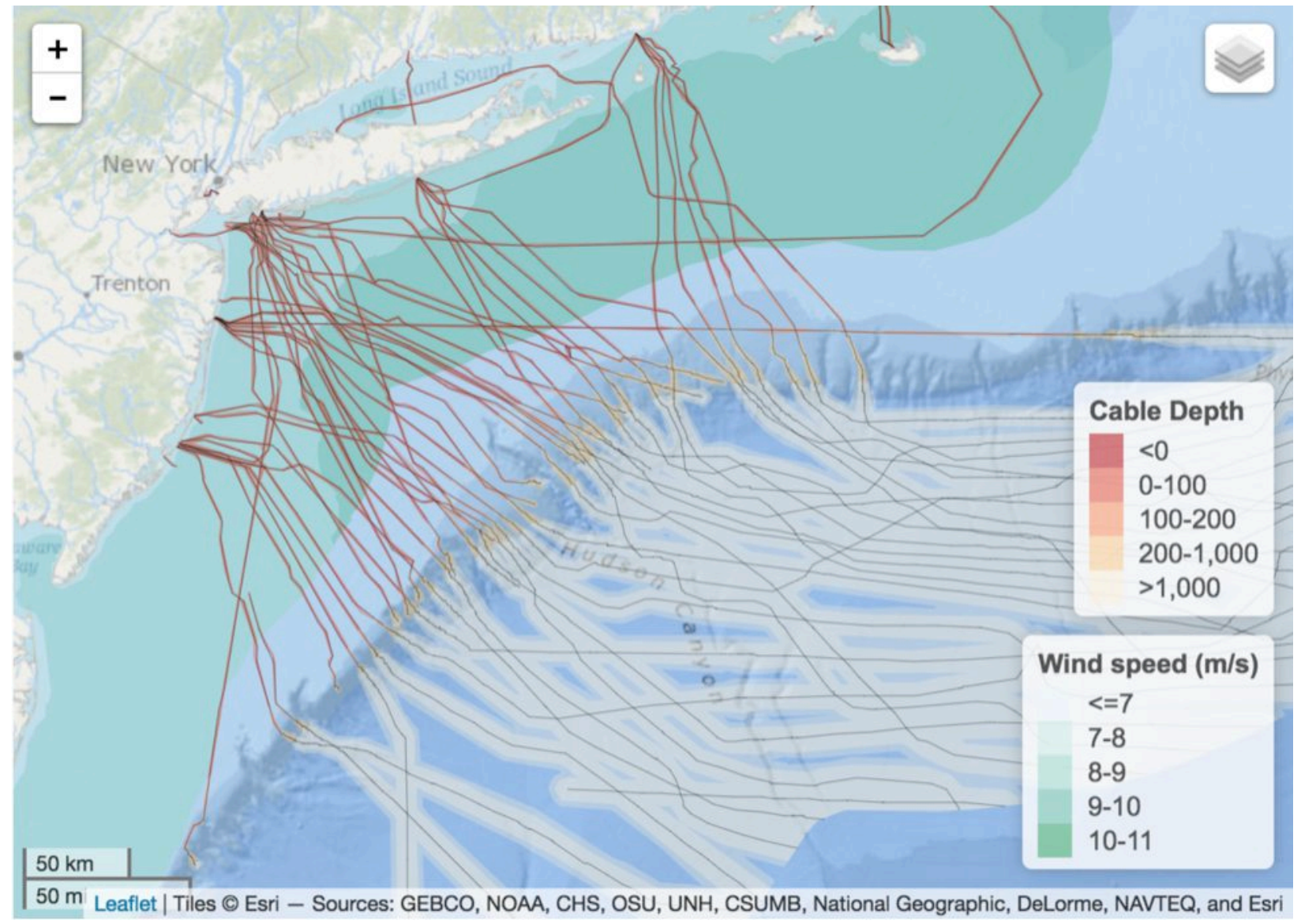

Figure 11. Viable wind energy area (green) and advisory $3 z$ cable setbacks (red) along the midAtlantic bight. The background contextual map layer is provided by Esri (2019) 


\section{Discussion}

The proposed avoidance areas for submarine cables are advisory and hold no legal or regulatory function. A site that overlaps with existing submarine cable setbacks does not nullify the possibility of developing renewable energy in that location. Rather, it should alert the developer to the potential for conflict and the need for engaged consultation with cable operators and other relevant parties. Specifying legal responsibilities is outside the scope of this report and a matter specific to the configurations and requirements of the proposed marine renewable energy facility and cable operator. The cable setbacks have been defined according to traditional methods of submarine cable repair involving grappling of the submarine cable and buoying to the surface for repair, hence allowing for sway of the boat as a function of depth. In the future, the use of more sophisticated dynamic positioning systems and remotely operated vehicles may narrow safe operating distances.

The avoidance areas published in this report are limited to the most recent publicly available data set on cable location, which is only as current as 2012. Meanwhile, new submarine cables continue to be introduced. Any planning for marine renewable energy development should consult the latest electronic navigation charts ${ }^{16}$ for any submarine cables. We also recommend consulting submarine cable information that can be found at SubmarineCableMap.com, which includes owner contact information, length, and ready-for-service dates (Figure 12) of new and planned cables. The cable route data available on SubmarineCableMap.com are from cable industry organizations, such as the North American Submarine Cable Association ${ }^{17}$ or the International Cable Protection Committee, ${ }^{18}$ which are also available for such queries.

\footnotetext{
${ }^{16}$ NOAA electronic navigation charts: https://www.nauticalcharts.noaa.gov/charts/noaa-enc.html

${ }^{17}$ North American Submarine Cable Association: https://www.n-a-s-c-a.org

${ }^{18}$ International Cable Protection Committee: https://www.iscpc.org
} 


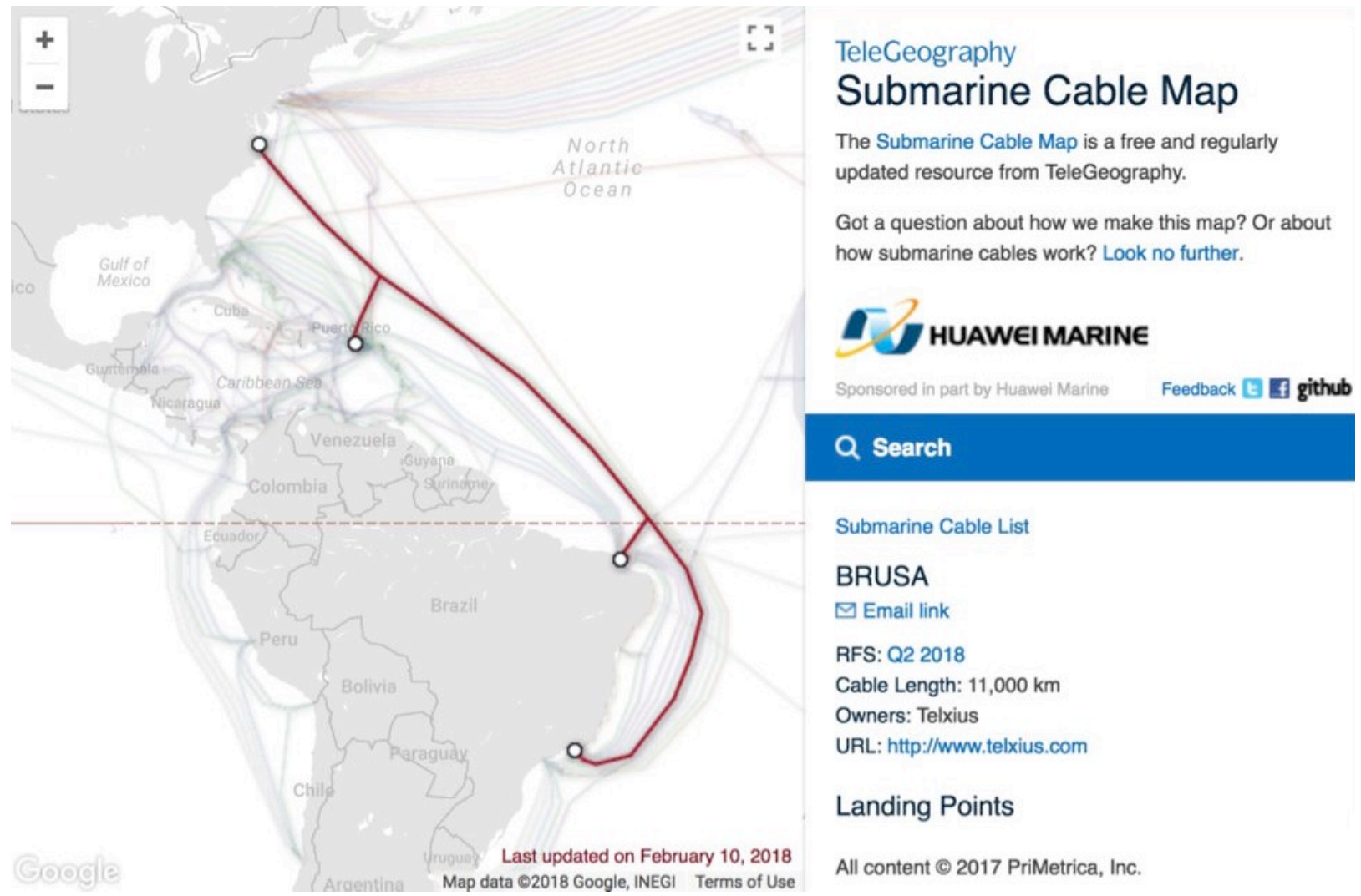

Figure 12. Screenshot of SubmarineCableMap.com; data include cable owner contact information, cable length, and ready-for-service dates (right)

This technical report provides value as long as marine renewable energy continues to be pursued in the United States. Although the United States currently only has one marine renewable energy facility in full production (30 MW), at Block Island Wind Farm (Rhode Island), the total pipeline for offshore wind energy is orders of magnitude higher (25,824 MW) as of June 2019 (Figure 13) (Musial et al. 2019), with significant future potential further identified (Beiter et al. 2017; Lehmann et al. 2017; Uihlein and Magagna 2016). 


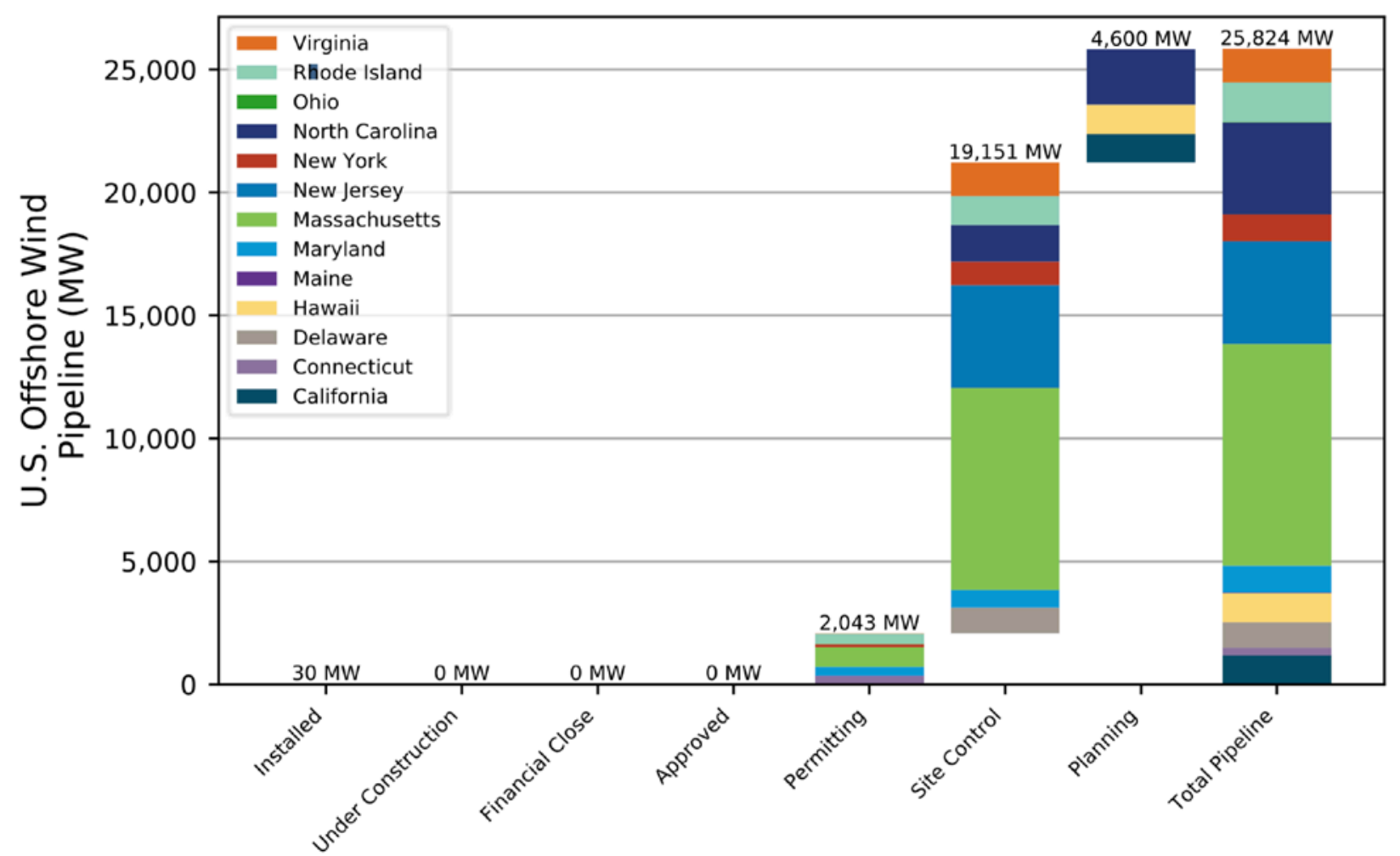

Pipeline Classification

Figure 13. U.S. offshore wind project pipeline by project status as of June 2019 Source: Musial et al. (2019)

For instance, the Virginia wind energy area offshore from Virginia Beach currently has five proposed/ongoing offshore wind-related activities with some potential for conflict given three submarine cables ready for service in the near future, discoverable via SubmarineCableMap.com (Figure 12): MAREA (first quarter 2018), Midgardsormen (first quarter 2019), BRUSA (first quarter 2018). In New York, the U.S. Department of the Interior auctioned nearly 80,000 acres offshore for commercial wind energy development in December 2016. New Jersey has two renewable energy leases signed by BOEM as of February 2016. In Massachusetts, BOEM approved the site assessment plan for a lease with Bay State Wind in June 2017 and is in process with another offshore lease between Statoil Wind and PNE Wind with bids received in January 2017. In Rhode Island, besides the existing Block Island Wind Farm, BOEM is reviewing a site assessment plan for the north lease area received from Deepwater Wind in April 2016. In December 2016 in Delaware, BOEM approved the assignment of an offshore wind lease to GSOE I. In Oregon, Oregon State University's Northwest National Marine Renewable Energy Center is in the permitting phase to develop the Pacific Marine Energy Center-South Energy Test Site facility for testing wave energy converters. In California, a competitive bidding process is underway between Trident Winds and Statoil Wind for an offshore area near Morro Bay and BOEM published three Call Areas for offshore wind development of 2,784 $\mathrm{km}^{2}(687,823$ acres) with potential to generate 8.4 gigawatts (Musial et al. 2019). In Hawaii, BOEM is in the area identification stage of the leasing process for two call areas north and south of Oahu. These activities indicate that marine renewable energy is a growing sector of energy development, and these projects will need to consider existing and future cable routes in their project development plans to reduce the risk of conflict with other cable stakeholders in their area. 


\section{Conclusion}

Marine renewable energy resources vary geographically and may interact with other human uses and natural resources. This work presents an analysis of the potential competing use between cables and marine renewable energy. We find that although there are some places where these industries might be competing for marine space, on average the overlap between viable marine renewable energy resource locations and existing cable routes is small.

The submarine cable industry provides critical power and telecommunication services; therefore, safe operation and maintenance must be heeded as marine renewable energy sources are developed (Communications Security, Reliability and Interoperability Council IV 2014, 2016). The submarine cable setback areas created and evaluated through this report are novel spatial planning data layers intended to minimize conflict with the submarine cable industry at the early planning stages of marine renewable energy development.

By evaluating overlap of these cable safety avoidance zones with availability of viable marine renewable energy, we conclude that on average, overlap is minimal for grid-scale development with the current generation of technology: tidal (3.8\%), wave (0.9\%), and wind (4\%) (Table 3). These numbers cannot be interpreted as an exact fraction of total resource - in units of power or energy/year - that overlaps with cable routes, but they do serve as a proxy for that value. We have taken this approach because it is consistent across resource types, and it does not require making subjective decisions about array layout configurations. At the highest level, this report shows that cable routes have minimal overlap with marine renewable energy resources. Furthermore, the possibility that some fraction of these areas might be excluded from marine renewable energy development does not significantly reduce the magnitude of the total U.S. marine renewable energy resource.

This picture of minimal overlap, however, is fairly simplistic in nature and may change as cable routes are added and removed and our understanding of viable marine renewable energy resources evolves (either because of technological changes or changes in resource distribution estimates). Furthermore, a detailed investigation of the potential overlap between the most promising marine energy sites (i.e., early market sites) and cable routes is left for future work. Furthermore, that work should consider more competing-use factors in the analysis, as cable owner/operators may not be the most restrictive stakeholders at potential sites.

In this report, we used the $3 \mathrm{z}$ (500 m wide, or three times the water depth) setback distance to highlight the potential that a cable owner is a stakeholder at a site. However, the legal right of way of a cable is only $200 \mathrm{ft}(61 \mathrm{~m})$ wide. Zooming into specific areas and energy bins reveals a few specific areas where the $3 \mathrm{z}$ overlap is higher than average, such as the aforementioned Puget Sound for tidal energy or Hawaii for wind. However, overlap does not nullify the possibility of marine renewable energy development. In these instances, this advisory product flags areas where cable owners are stakeholders as a prompt for the marine renewable energy developer to either find an alternative site or engage in proactive negotiations with the submarine cable operator for safe repair and maintenance of the submarine cables. 


\section{References}

Beiter, Philipp, Walter Musial, Levi Kilcher, Michael Maness, Aaron Smith. 2017. An Assessment of the Economic Potential of Offshore Wind in the United States from 2015 to 2030. Golden, CO: National Renewable Energy Laboratory. NREL/TP-6A20-67675. https://tethys.pnnl.gov/sites/default/files/publications/Beiter-et-al-2017-NETL.pdf

Bureau of Ocean Energy Management. undated. "State Activities." https://www.boem.gov/Renewable-Energy-State-Activities/.

Communications Security, Reliability and Interoperability Council IV. 2014. Working Group 8 Submarine Cable Routing and Landing. Protection of Submarine Cables Through Spatial Separation. http://transition.fcc.gov/pshs/advisory/csric4/CSRIC_IV_WG8_Report1_3Dec2014.pdf.

Communications Security, Reliability and Interoperability Council IV. 2016. Working Group 4A Submarine Cable Resiliency. Final Report-Clustering of Cables and Cable Landings. https://www.atis.org/01_legal/docs/CSRIC\%20V/WG4A_Final_091416.pdf.

Esri. 2019. “Ocean Basemap. http://esriurl.com/obm.

Flanders Marine Institute. 2016. "Maritime Boundaries Geodatabase: Maritime Boundaries and Exclusive Economic Zones (200NM), version 9." Available online at http://www.marineregions.org/. Accessed April 25, 2017. Maritime Boundaries Geodatabase: https://doi.org/10.14284/317.

Haas, Kevin A., Hermann Fritz, Steven P. French, Brenna T. Smith, Vincent Neary. 2011. Assessment of Energy Production Potential from Tidal Streams in the United States. Atlanta, GA: Georgia Tech Research Corporation. https://www.osti.gov/scitech/servlets/purl/1219367.

Jacobson, Paul T., George Hagerman, and George Scott. 2011. Mapping and Assessment of the United States Ocean Wave Energy Resource. Palo Alto, CA: Electric Power Research Institute. http://www.osti.gov/scitech/servlets/purl/1060943.

Kilcher, Levi, and Robert Thresher. 2016. Marine Hydrokinetic Energy Site Identification and Ranking Methodology Part I: Wave Energy. Golden, CO: National Renewable Energy Laboratory. NREL/TP-5000-66038. https://www.osti.gov/scitech/biblio/1330617.

Kilcher, Levi, Robert Thresher, and Heidi Tinnesand. 2016. Marine Hydrokinetic Energy Site Identification and Ranking Methodology Part II: Tidal Energy. Golden, CO: National Renewable Energy Laboratory. NREL/TP-5000-66079.

https://www.osti.gov/scitech/biblio/1330619-marine-hydrokinetic-energy-site-identificationranking-methodology-part-ii-tidal-energy.

Lehmann, Marcus, Farid Karimpour, Clifford A. Goudey, Paul T. Jacobson, Mohammad-Reza Alam. 2017. "Ocean Wave Energy in the United States: Current Status and Future Perspectives." Renewable and Sustainable Energy Reviews, 74, 1300-1313. doi:10.1016/j.rser.2016.11.101. 
Lowndes, Julia S. Stewart, Benjamin D. Best, Courtney Scarborough, Jamie C. Afflerbach, Melanie R. Frazier, Casey C. O’Hara, Ning Jiang, Benjamin S. Halpern. 2017. "Our Path to Better Science in Less Time Using Open Data Science Tools." Nature Ecology \& Evolution, 1(6), 0160. doi:10.1038/s41559-017-0160.

Madeyski, L., and B. Kitchenham. 2015. "Reproducible Research-What, Why and How." Wroclaw University of Technology, PRE W, 8. http://madeyski.e-

informatyka.p1/download/MadeyskiKitchenham15.pdf. Accessed October 3, 2017.

Musial, Walt, Donna Heimiller, Philipp Beiter, George Scott, Caroline Draxl. 2016. 2016 Offshore Wind Energy Resource Assessment for the United States. Golden, CO: National Renewable Energy Laboratory. http://www.nrel.gov/docs/fy16osti/66599.pdf. Musial, Walter, Philipp Beiter, Paul Spitsen, Jake Nunemaker, and Vahan Gevorgian. 2019. 2018 Offshore Wind Technologies Market Report. Golden, CO: National Renewable Energy Laboratory (NREL). doi:10.2172/1559876. https://www.osti.gov/servlets/purl/1559876

OpenEI. 2019. Marine and Hydrokinetic Data Repository.

http://mhkdr.openei.org/submissions/3.

Schwartz, M., D. Heimiller, S. Haymes, W. Musial. 2010. Assessment of Offshore Wind Energy Resources for the United States. Golden, CO: National Renewable Energy Laboratory. https://www.nrel.gov/docs/fy10osti/45889.pdf.

Thomson, Jim, Brian Polagye, V. Durgesh, M. C. Richmond. 2012. "Measurements of Turbulence at Two Tidal Energy Sites in Puget Sound, WA." Journal of Oceanic Engineering 37, no. 3: 363-374. https://doi.org/10.1109/JOE.2012.2191656.

Uihlein, Andreas, and Davide Magagna. 2016. "Wave and tidal current energy review of the current state of research beyond technology." Renewable and Sustainable Energy Reviews, 58, 1070-1081. http://www.sciencedirect.com/science/article/pii/S1364032115016676

VLIZ. 2017. “IHO Sea Areas, version 2.” http://www.marineregions.org/. Accessed July 2, 2017.

Weatherall, Pauline, K. M. Marks, Martin Jakobsson, Thierry Schmitt, Shin Tani, Jan Erik Arndt, Marzia Rovere, Dale Chayes, Vicki Ferrini, Rochelle Wigley. 2015. “A New Digital Bathymetric Model of the World's Oceans." Earth and Space Science, 2(8), $2015 \mathrm{EA} 000107$. doi:10.1002/2015EA000107. 


\section{Appendices}

The appendices include regional maps for every energy resource characterized with overlap of submarine cable separation safety buffers. The energy resource is color coded by intensity and submarine cable buffers by bottom depth. Please note that these layers are visible throughout the extent of the exclusive economic zone across all depths and energy bins; however, maximum depth limits and minimum viable energy intensities were imposed for evaluating overlap between the two.

Within the body of this report we zoomed into example areas worthy of discussion (Figures 611). The regional maps in these appendices are often too coarse to see meaningful details. The vast geographic scope of this report across all U.S. regions practically prohibits inclusion of comprehensive fine-scale maps within a static report. Although tiled maps at finer resolution could theoretically be populated throughout the appendices with navigational cues to neighboring pages (similar to the Thomas Guide road atlases of yore), such ballooning of the report is of questionable value. A better solution is providing the ability to interactively explore the maps online, which can be done via the site shown in Figure 14.

\section{Interactive Maps of Cable Buffers and Renewable Energy by U.S. Region} http://ecoquants.github.io/nrel-cables/maps.html

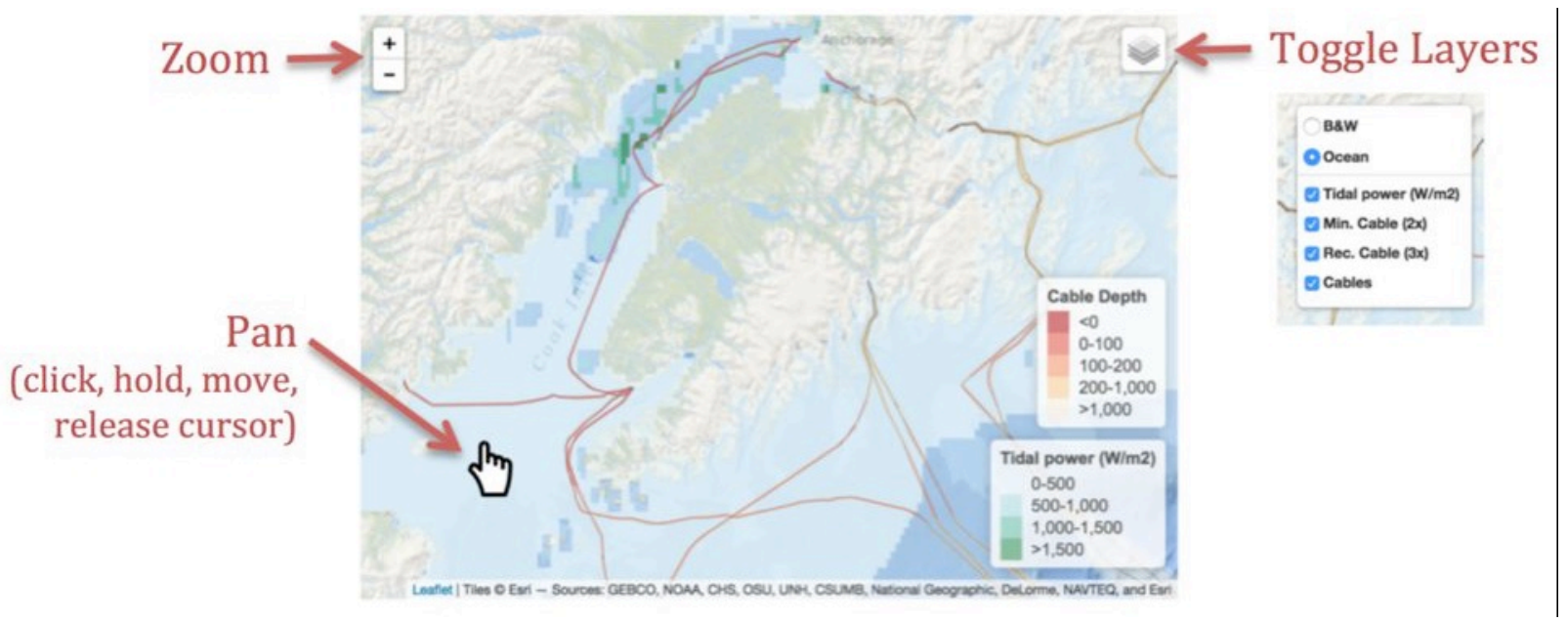

Figure 14. Interactive mapping functionality available via the online maps at http://ecoquants.github.io/nrel-cables/maps.html. The background contextual map layer is provided by Esri (2019) 


\section{Appendix A. Maps of Tidal Energy and Cable Setback by U.S. Region}

A.1 Alaska

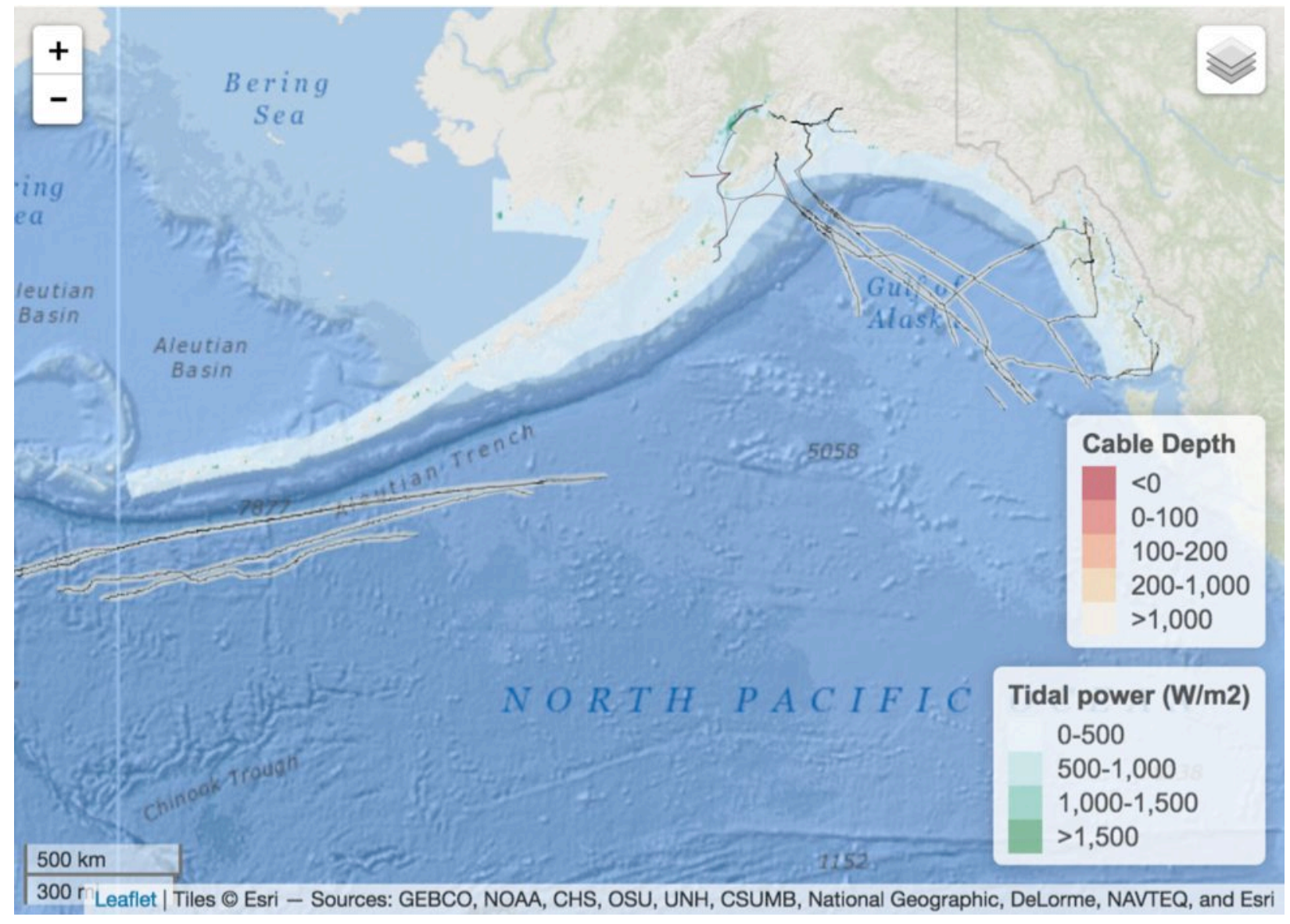

Figure A-1. Map of tidal power in Alaska (green) with submarine cables (black lines) and advisory $3 z$ setbacks colored by bottom depth (red). The background contextual map layer is provided by Esri

(2019) 


\section{A.2 East}

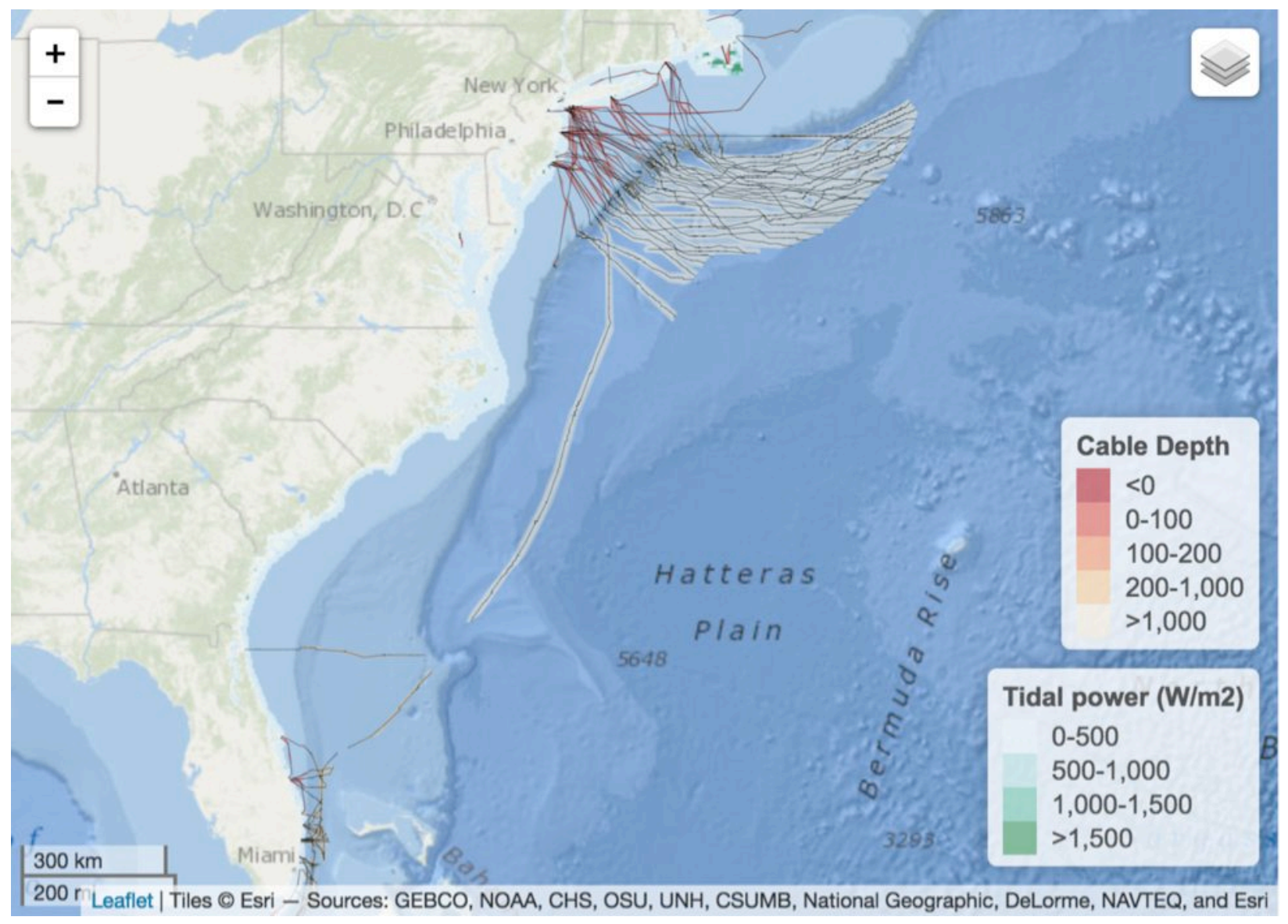

Figure A-2. Map of tidal power (green) in the East with submarine cables (black lines) and advisory $3 z$ setbacks colored by bottom depth (red). The background contextual map layer is provided by Esri (2019) 


\section{A.3 Gulf of Mexico}

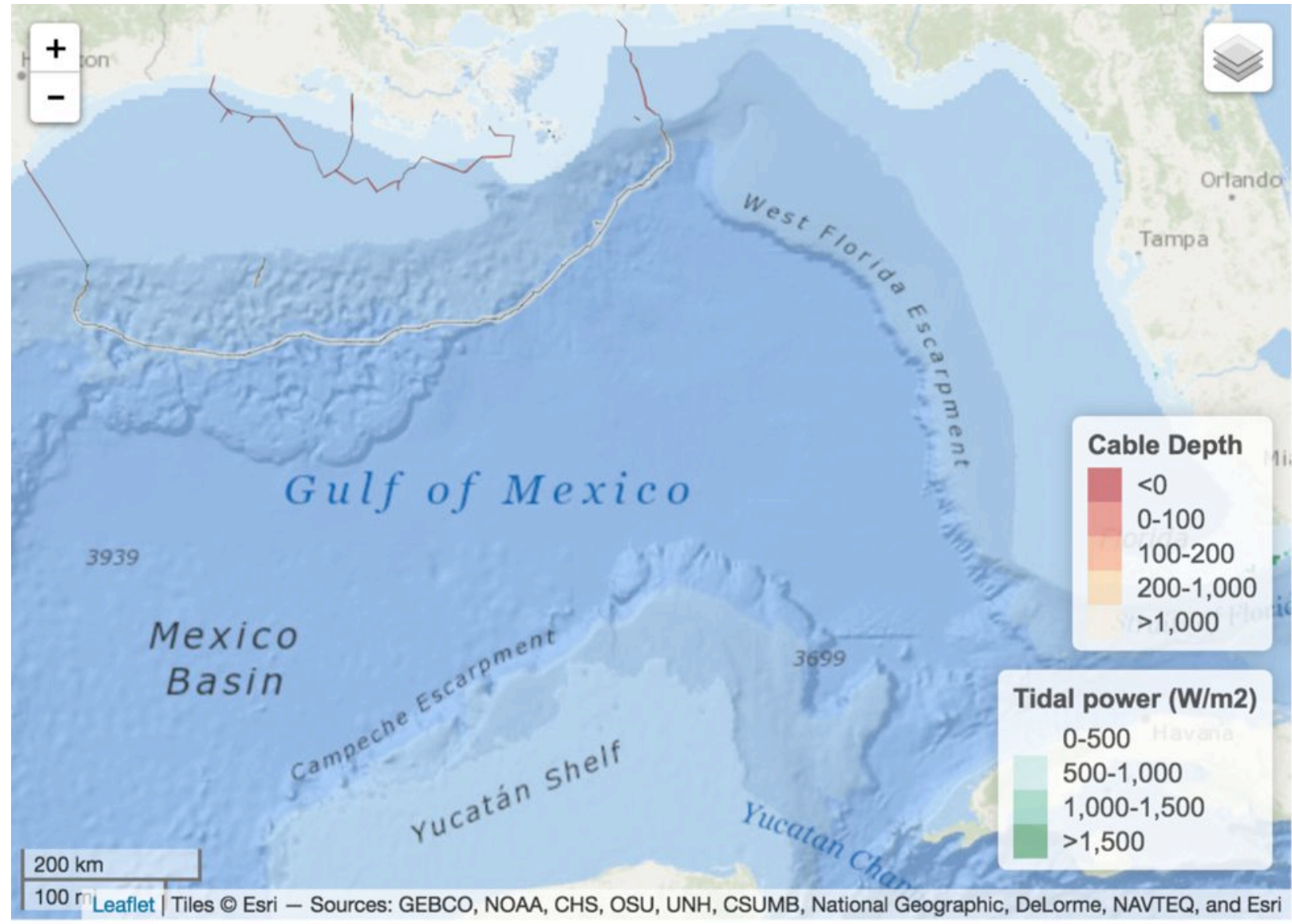

Figure A-3. Map of tidal power (green) in the Gulf of Mexico with submarine cables (black lines) and advisory buffers colored by bottom depth (red). The background contextual map layer is provided by Esri (2019) 


\section{A.4 Puerto Rico}

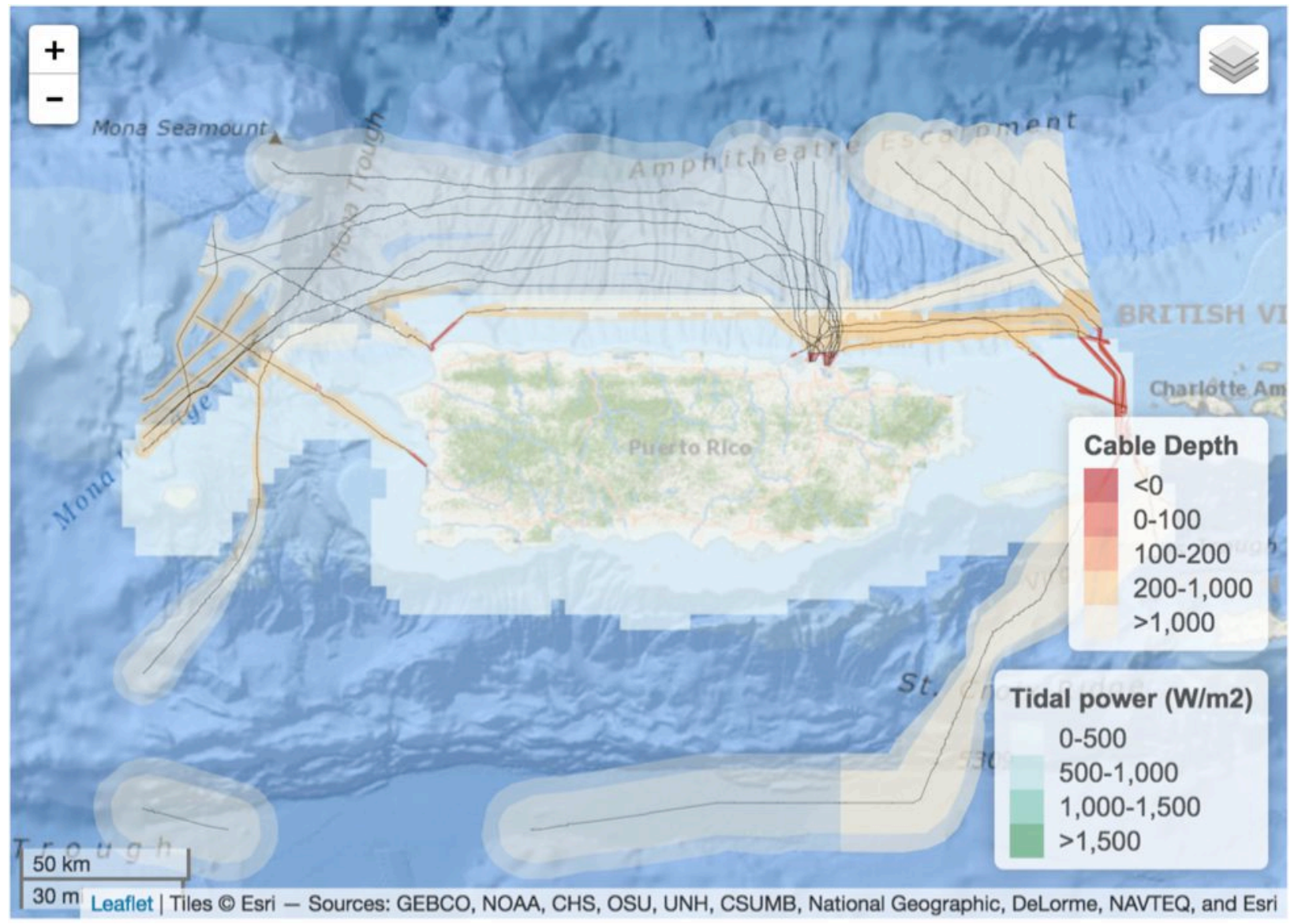

Figure A-4. Map of tidal power (green) in Puerto Rico with submarine cables (black lines) and advisory buffers colored by bottom depth (red). The background contextual map layer is provided by Esri (2019) 


\section{A.5 U.S. Virgin Islands}

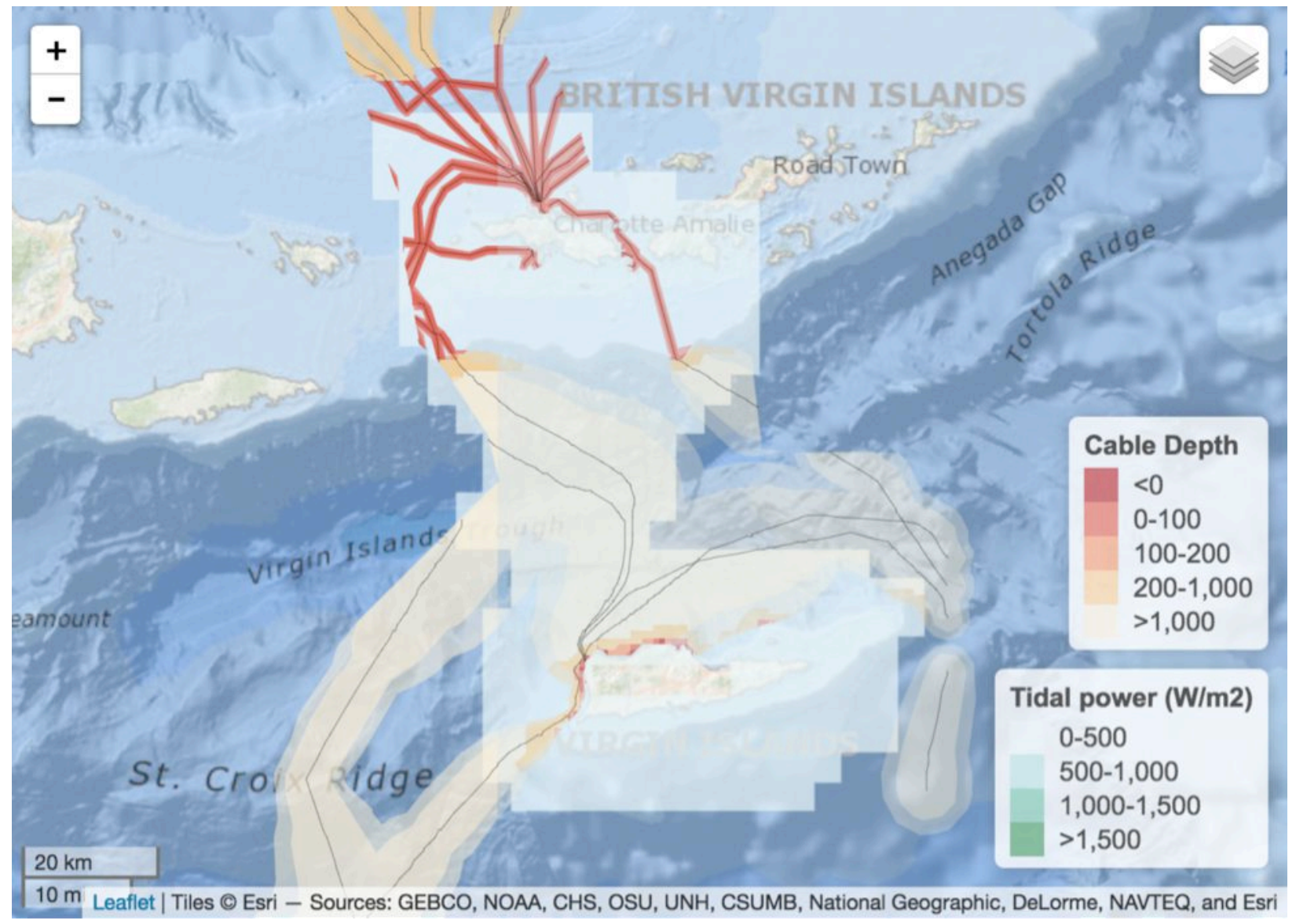

Figure A-5. Map of tidal power (green) in the U.S. Virgin Islands with submarine cables (black lines) and advisory buffers colored by bottom depth (red). The background contextual map layer is provided by Esri (2019) 


\section{A.6 West Coast}

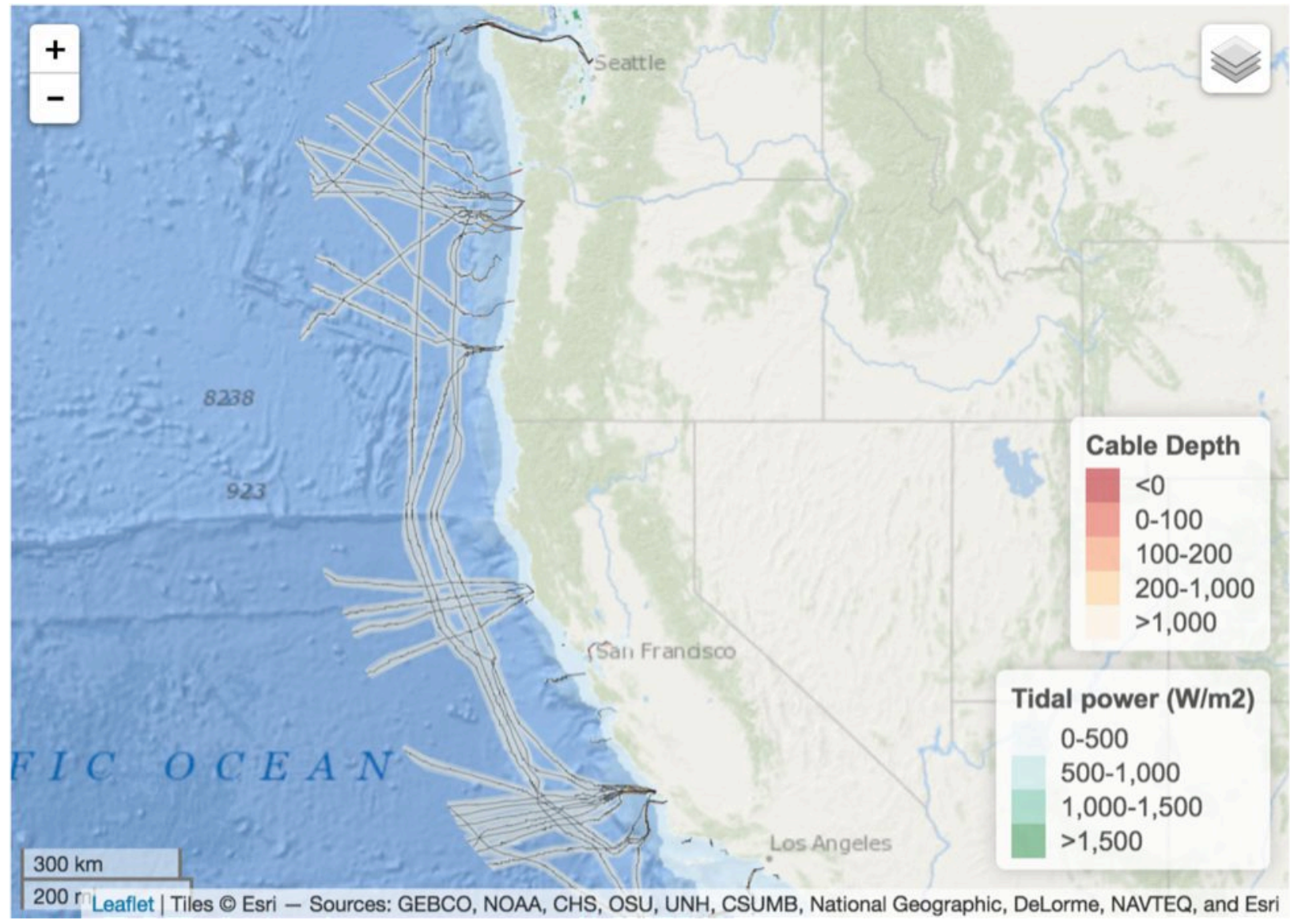

Figure A-6. Map of tidal power (green) in the West Coast with submarine cables (black lines) and advisory buffers colored by bottom depth (red). The background contextual map layer is provided by Esri (2019) 


\section{Appendix B. Maps of Wave Energy and Cable Setback by U.S. Region \\ B.1 Alaska}

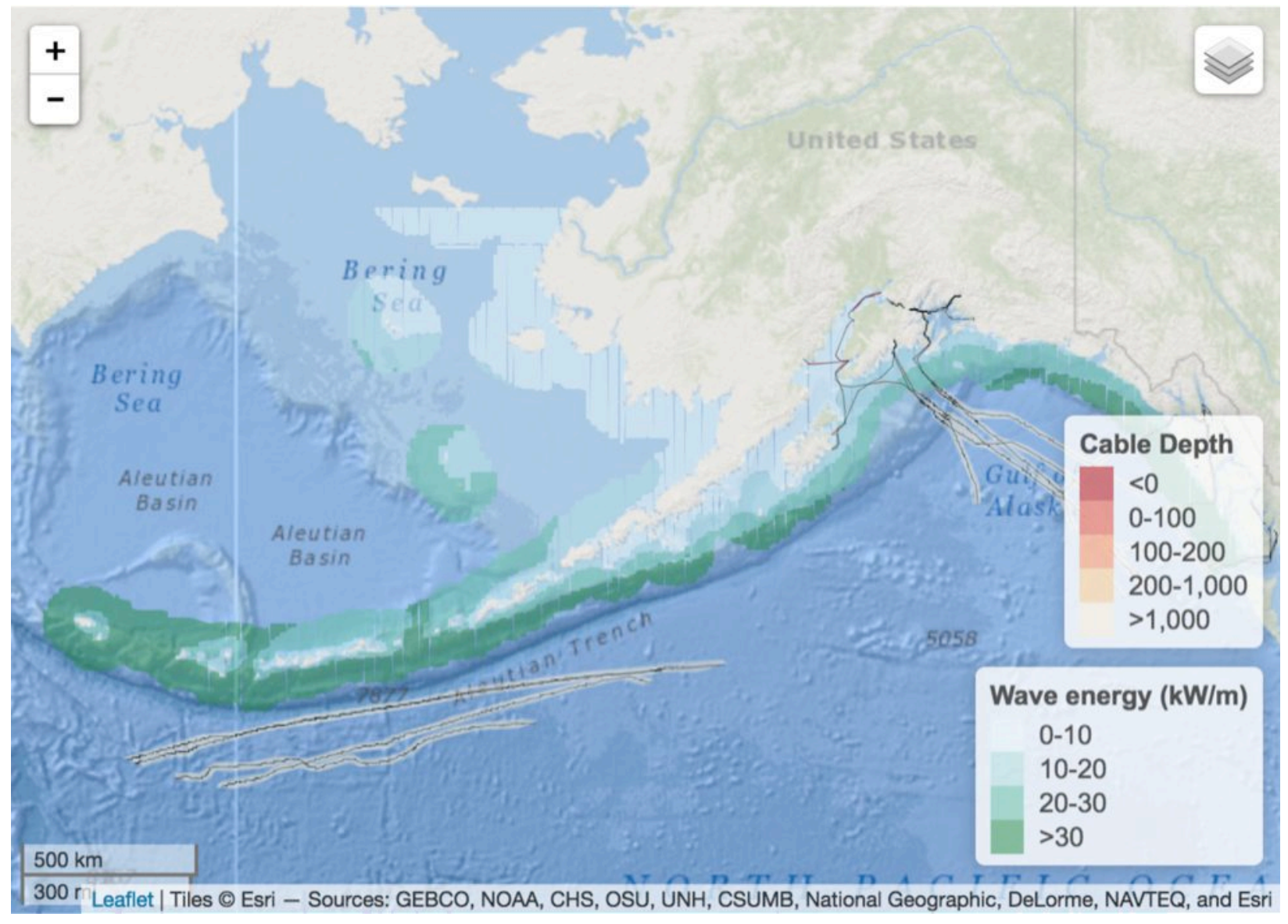

Figure 14. Map of wave energy (green) in Alaska with submarine cables (black lines) and advisory buffers colored by bottom depth (red). The background contextual map layer is provided by Esri (2019) 


\section{B.2 East Coast}

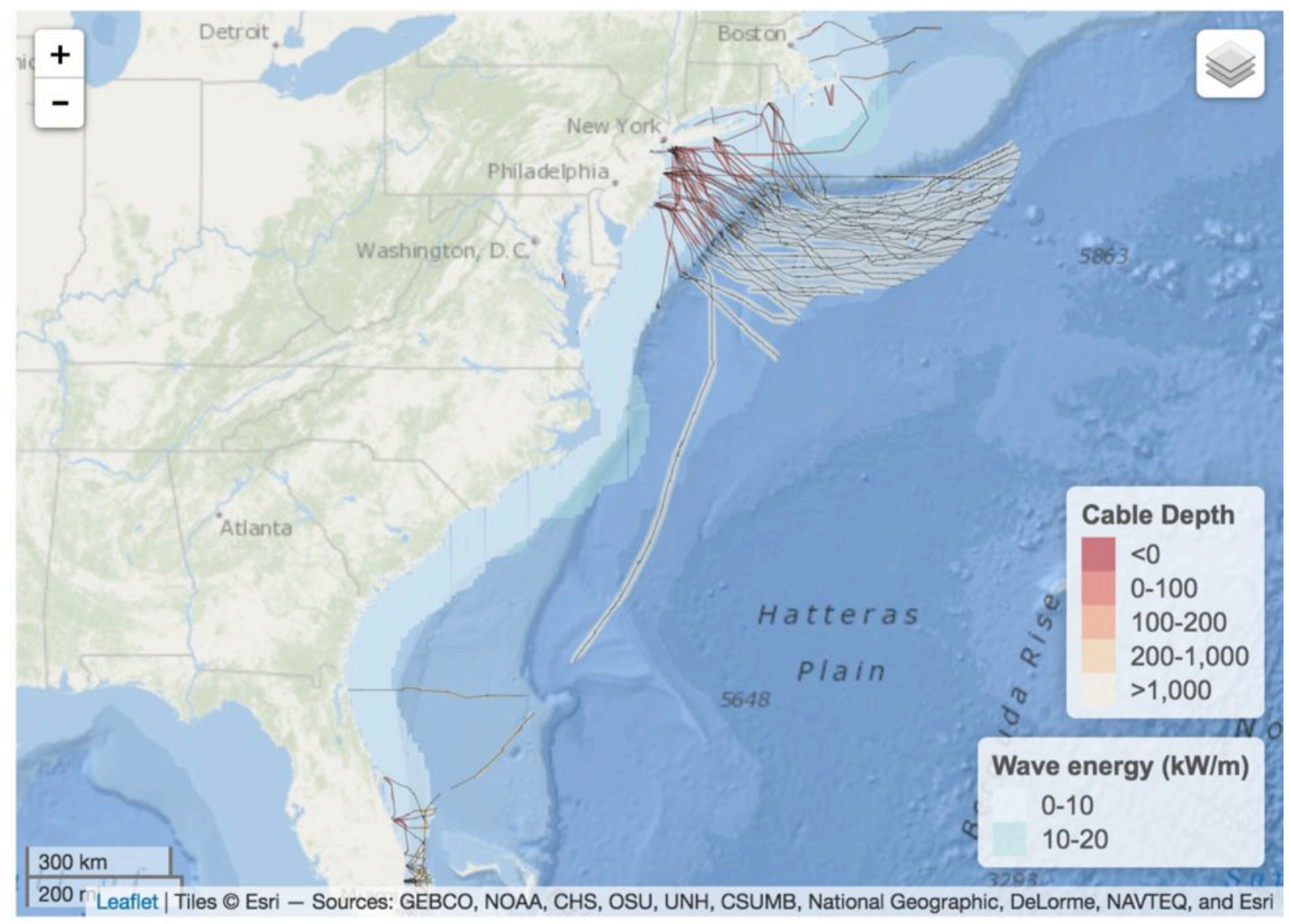

Figure 15. Map of wave energy (green) on the East Coast with submarine cables (black lines) and advisory buffers colored by bottom depth (red). The background contextual map layer is provided by Esri (2019) 


\section{B.3 Gulf of Mexico}

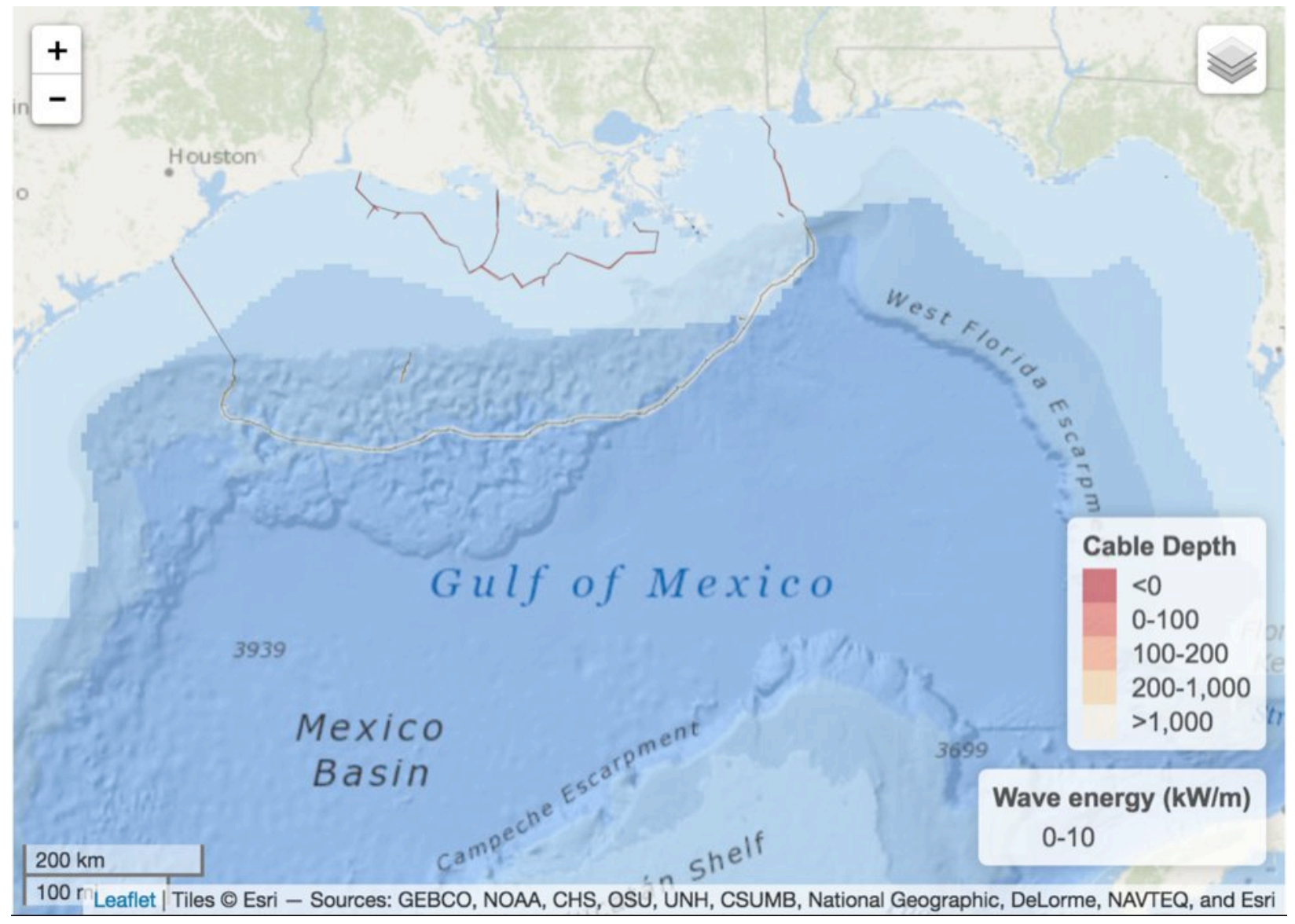

Figure 16. Map of wave energy (green) in the Gulf of Mexico with submarine cables (black lines) and advisory buffers colored by bottom depth (red). The background contextual map layer is provided by Esri (2019) 


\section{B.4 Hawaii}

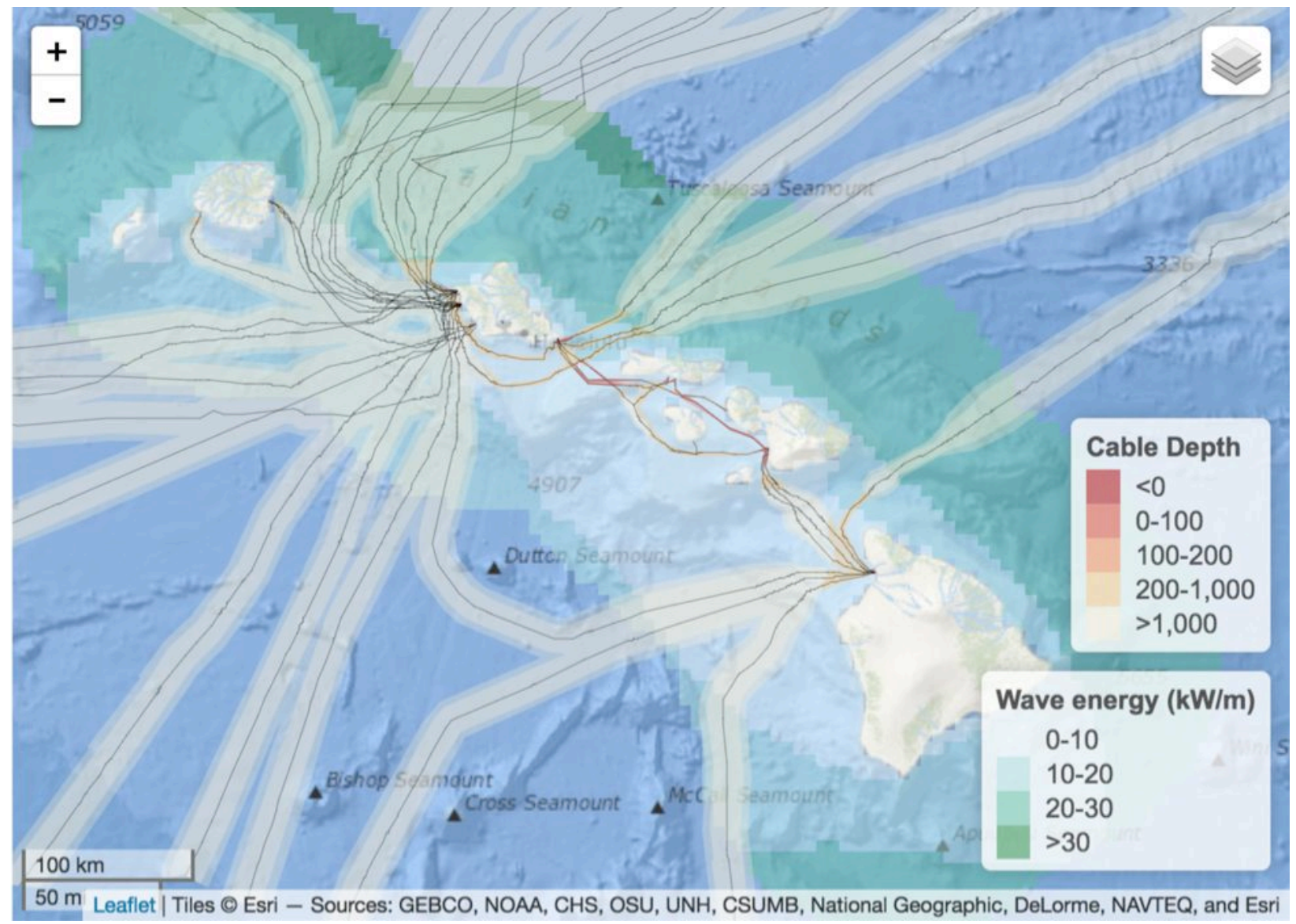

Figure 17. Map of wave energy (green) in Hawaii with submarine cables (black lines) and advisory buffers colored by bottom depth (red). The background contextual map layer is provided by Esri (2019) 


\section{B.5 Puerto Rico}

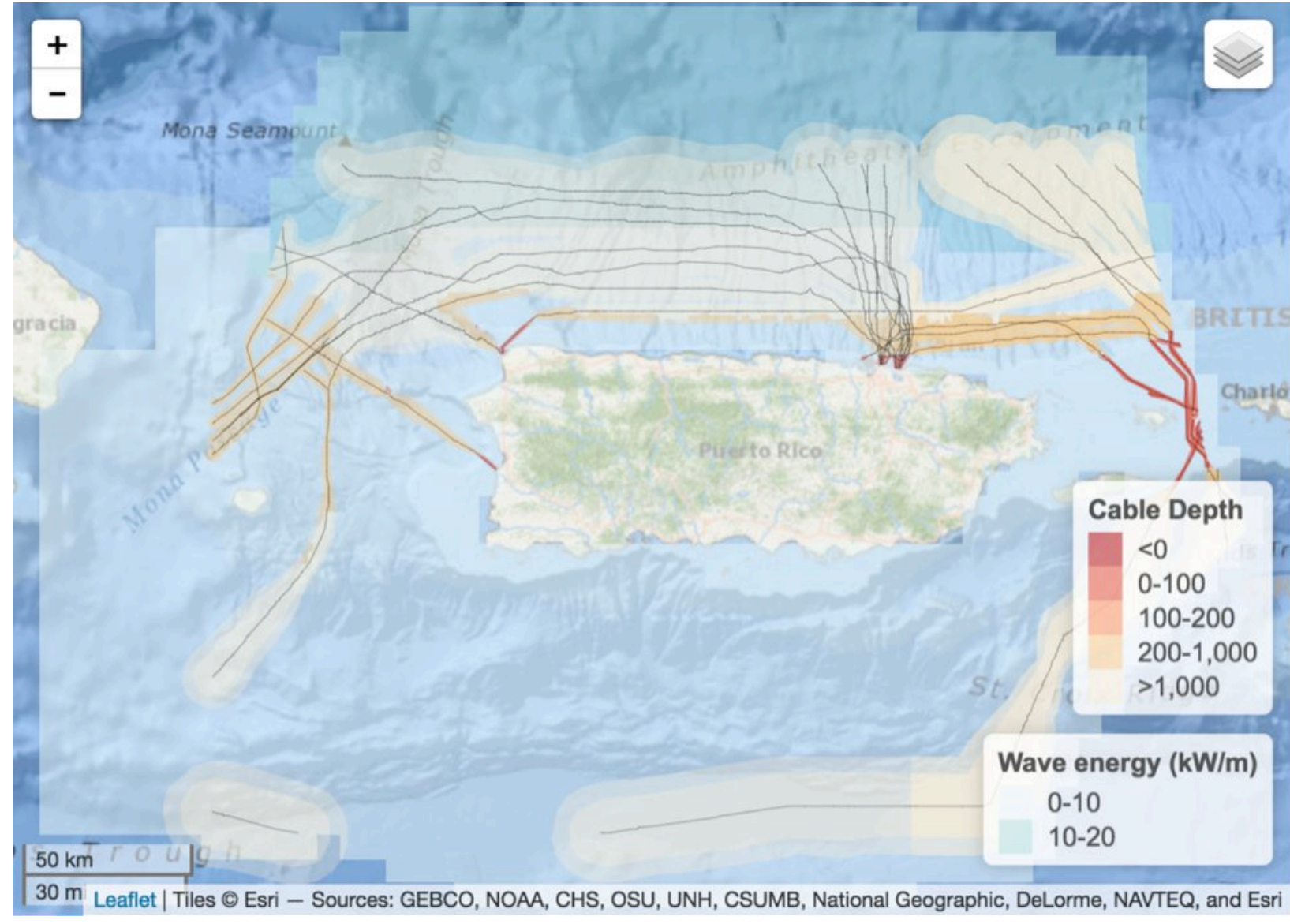

Figure 18. Map of wave energy (green) in Puerto Rico with submarine cables (black lines) and advisory buffers colored by bottom depth (red). The background contextual map layer is provided by Esri (2019) 


\section{B.6 U.S. Virgin Islands}

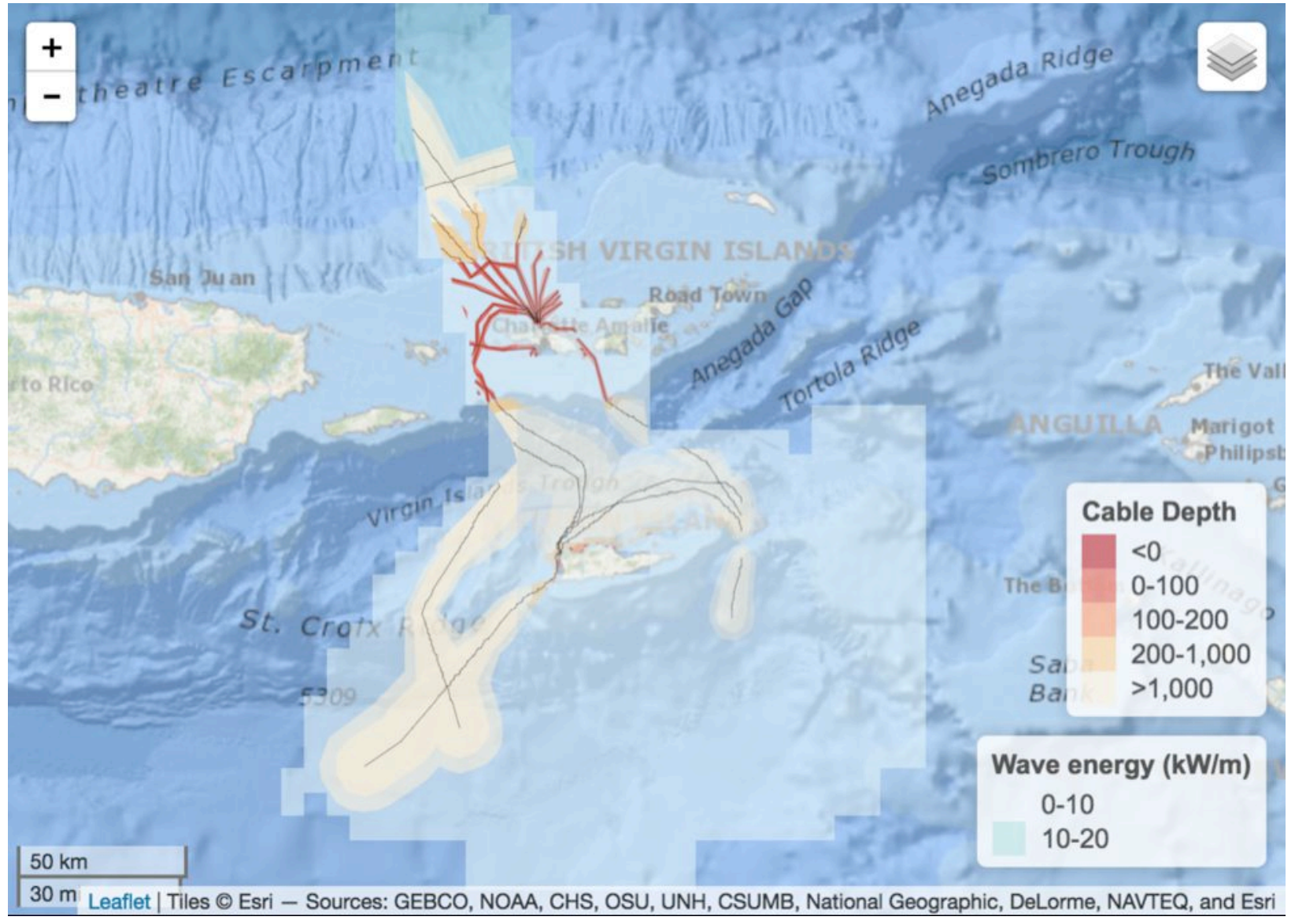

Figure 19. Map of wave energy (green) in the U.S. Virgin Islands with submarine cables (black lines) and advisory buffers colored by bottom depth (red). The background contextual map layer is provided by Esri (2019) 


\section{B.7 West Coast}

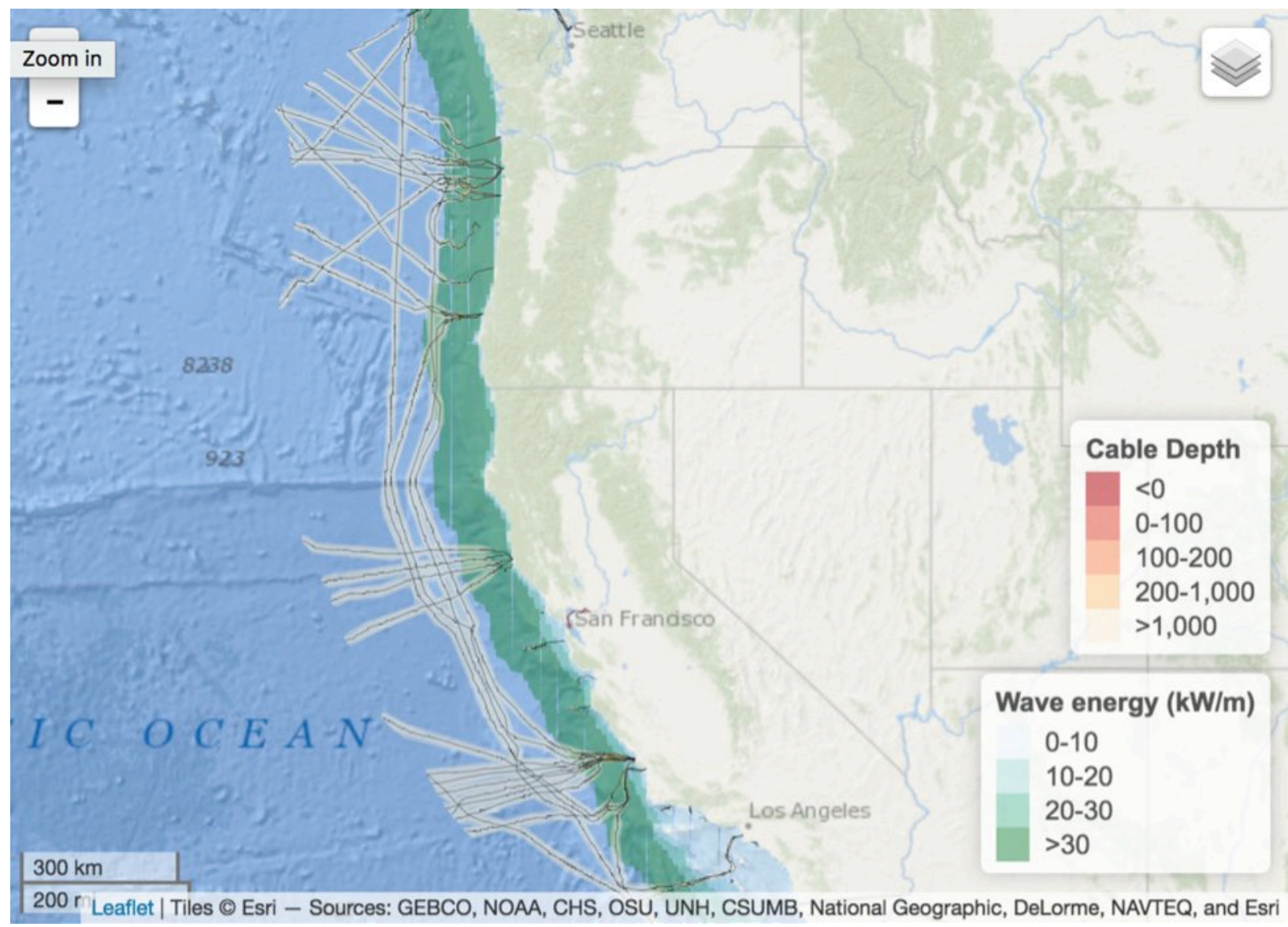

Figure 20. Map of wave energy (green) in the West Coast with submarine cables (black lines) and advisory buffers colored by bottom depth (red). The background contextual map layer is provided by Esri (2019) 


\section{Appendix C. Maps of Wind Energy and Cable Buffer by U.S. Region \\ C.1 East Coast}

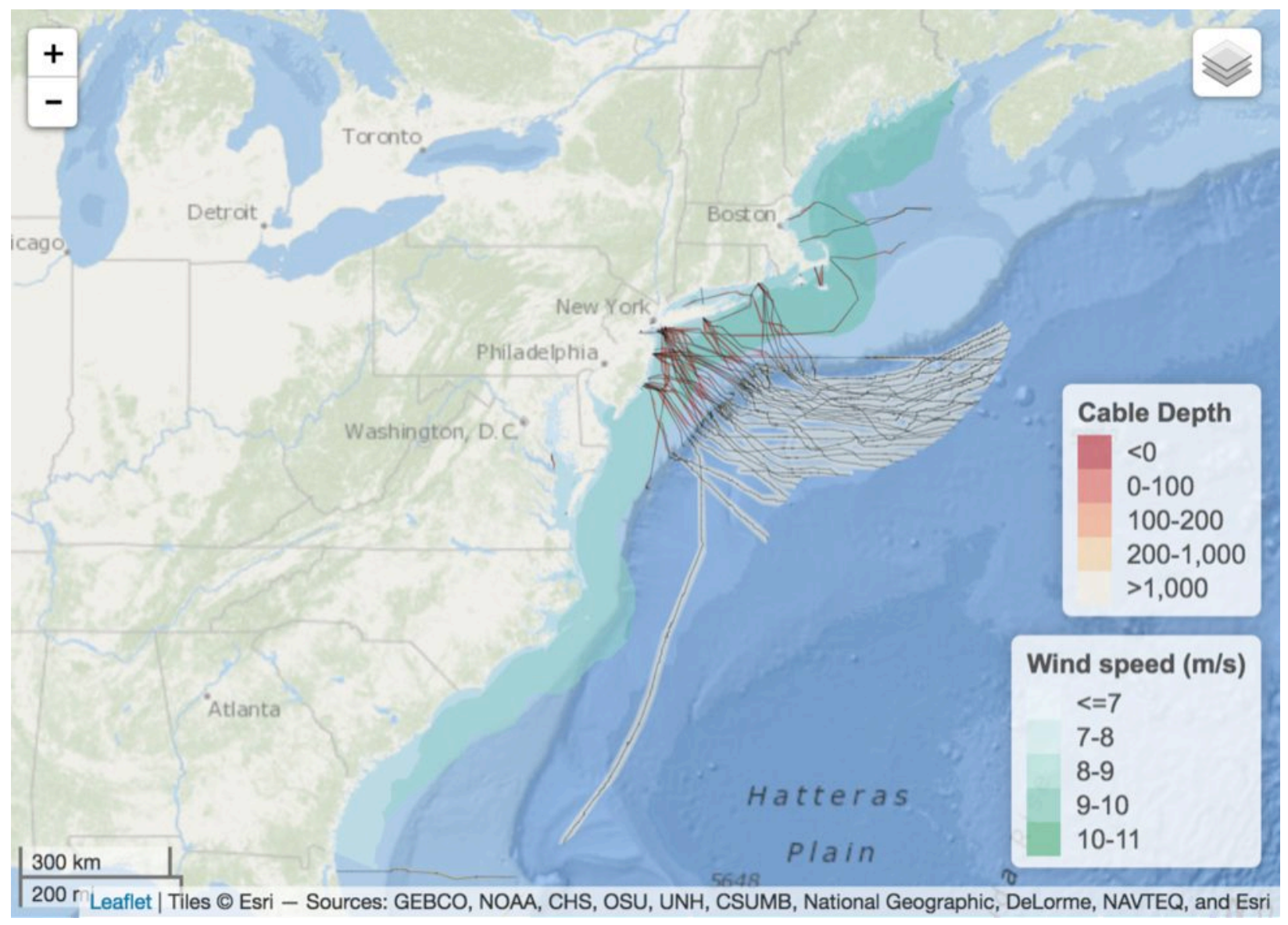

Figure C-1. Map of wind speed (green) in the East Coast with submarine cables (black lines) and advisory buffers colored by bottom depth (red). The background contextual map layer is provided by Esri (2019) 


\section{C.2 Gulf of Mexico}

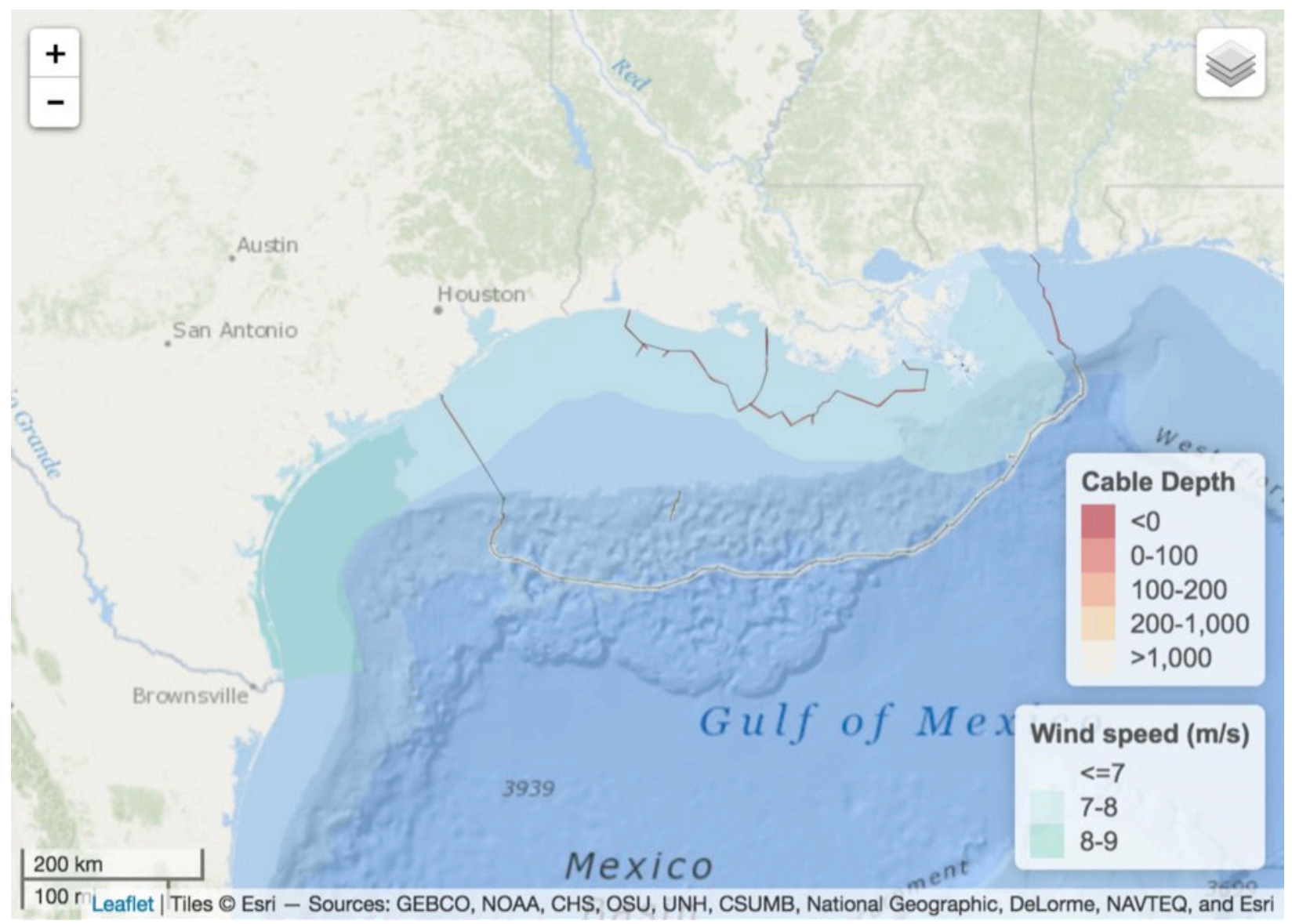

Figure C-2. Map of wind speed (green) in the Gulf of Mexico with submarine cables (black lines) and advisory buffers colored by bottom depth (red). The background contextual map layer is provided by Esri (2019) 


\section{C.3 Hawaii}

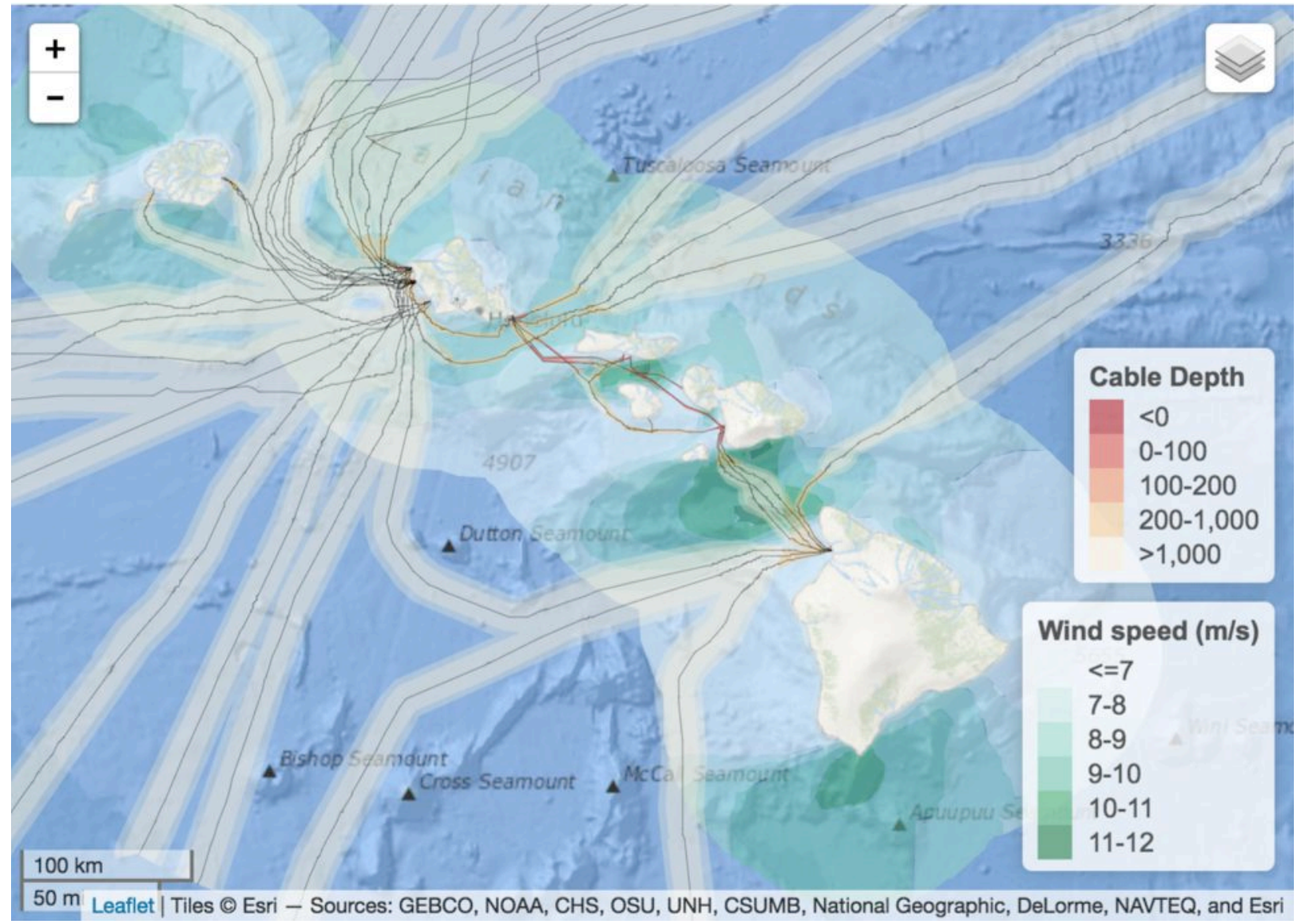

Figure C-3. Map of wind speed (green) in Hawaii with submarine cables (black lines) and advisory buffers colored by bottom depth (red). The background contextual map layer is provided by Esri (2019) 


\section{C.4 West Coast}

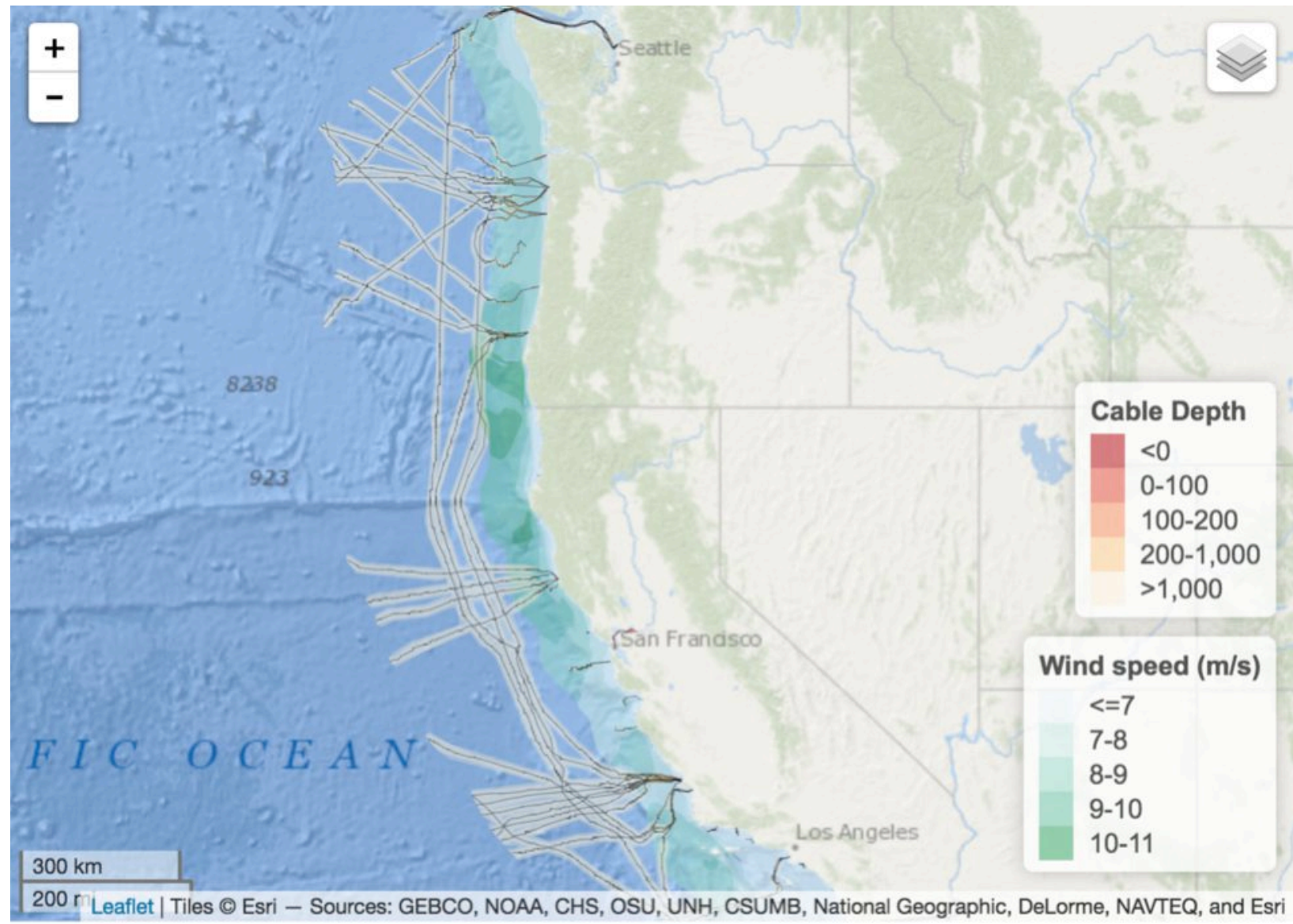

Figure C-4. Map of wind speed (green) in the West with submarine cables (black lines) and advisory buffers colored by bottom depth (red). The background contextual map layer is provided by Esri (2019) 